Article

\title{
Harsh Sliding Wear of a Zirconia Ball against a-C:H Coated CoCrMo Disc in Hyaluronic Gel
}

\author{
Annett Dorner-Reisel ${ }^{1, *}$, Christian Schürer ${ }^{2}$ and Stefan Svoboda ${ }^{3}$ \\ 1 Faculty of Mechanical Engineering, Schmalkalden University of Applied Sciences, Blechhammer 4-9, \\ D-98754 Schmalkalden, Germany \\ 2 Consultant Chemnitz, Germany, Oberfrohnaer Straße 16a, D-09117 Chemnitz, Germany; \\ cschuerer@online.de \\ 3 Faculty of Electrical Engineering, University of Applied Sciences Schmalkalden, Blechhammer 4-9, \\ D-98754 Schmalkalden, Germany; s.svoboda@hs-sm.de \\ * Correspondence: a.dorner-reisel@hs-sm.de
}

Received: 13 January 2020; Accepted: 6 March 2020; Published: 23 March 2020

\begin{abstract}
The a-C:H (amorphous carbon-hydrogen) films belong to the family of DLC (diamond-like carbon) coatings. The a-C:H coating was deposited on medical grade CoCrMo substrates by plasma-assisted chemical vapor deposition (PA-CVD) using benzene as gaseous precursor. Benzene offers an aromatic structure, which affects the a-C:H properties after plasma decomposition. A zirconia ball was sliding at two different frequencies, $50 \mathrm{~Hz}$ or $1 \mathrm{~Hz}$, against the uncoated and a-C:H coated CoCrMo. The frequency of $1 \mathrm{~Hz}$ is typical for human movement during fast walking. The harsh sliding conditions with a normal load of $100 \mathrm{~N}$ and $50 \mathrm{~Hz}$ frequency simulate extreme overloading of the biomedical sliding partners. It gives insight into the failure mechanisms. The wear tests were carried out in laboratory air (dry, RH: 15.6\%) or using hyaluronic gel as lubricant. The hyaluronic gel acts as an effective intermediate medium. It adheres very well to both, a-C:H coating and zirconia. No wear was evident on the $\mathrm{ZrO}_{2}$ ball at $1 \mathrm{~Hz}$ and $100 \mathrm{~N}$. Minor wear traces were observed on the a-C:H coating only. A wear coefficient of $0.16 \times 10^{-6} \mathrm{~mm} / \mathrm{N} \cdot \mathrm{m}$ were calculated for a-C:H coated CoCrMo after $\mathrm{ZrO}_{2}$ ball sliding with $1 \mathrm{~Hz}$ and $100 \mathrm{~N}$ in hyaluronic gel. This is two orders of magnitude lower in comparison to dry sliding of $\mathrm{ZrO}_{2}$ ball against DLC coated CoCrMo with $1 \mathrm{~Hz}$. The coefficient of friction (COF) remained below 0.09 until the hyaluronic gel starts to lose viscosity. This finding pronounces the importance of a proper homogeneous lubrication during operation of the biomedical joints. For extreme harsh tribological loading like sudden jumps of a patient with artificial joints, the application of an intermediate layer before a-C:H coating needs further evaluation.
\end{abstract}

Keywords: diamond-like carbon (DLC); amorphous carbon hydrogen (a-C:H); hyaluronic gel; sliding wear; Raman spectroscopy

\section{Introduction}

Hyaluronic acid is the main component of synovial liquid, the lubricating substance between articulating partners in natural joints. It provides ultra-low friction. Synovia is a viscous body fluid with clear appearance. It is produced by the membrana synovialis, which covers the articular capsule inside. During loading and movement of the femur, synovial liquid is squeezed out into the natural joints. Kung et al. [1] describe the importance of preserving the integrity of joint including the synovial lining and natural lubricating fluid properties for future successful implant survivorship.

Artificial joints contain CoCrMo alloys often, because of their wear resistance. The metallic CoCrMo is either just a part of the articulating joint, like the ball in a hip joint or the femur in a knee joint, or both articulating partners are made of metallic CoCrMo. Although artificial joint implants 
are produced on a high quality level already, some problems can arise from metallic ions or wear particles [2]. Blood cobalt and chromium levels of greater than $7 \mathrm{ppb}(7 \mu \mathrm{g} / \mathrm{L})$, point to potential for undesired soft tissue reaction [2]. Even if, the articulating part in the artificial joint is a softer polymer, like UHMWPE (ultra-high molecular weight polyethylene), the metallic counterpart suffers from wear. Alternatively, special designed surface modifications-i.e., inorganic carbon allotropes—can be applied to reduce ion and wear particle release. Care must be taken in order to ensure proper adherence and durability of surface modifications.

The motivation of the present study is exploring the suitability and limits of a potential surface modification by diamond-like carbon coatings on CoCrMo metallic alloy. As mentioned before, medical grade CoCrMo implants over excellent wear resistance under proper conditions, but as a partner in the articulating couple, they slowly are abraded to a certain extent. A DLC coating should reduce their abrasive wear. Furthermore, DLC as a carbon surface modification could provide sufficient hosting for synovia in artificial joints. Inorganic carbon modifications are known to provide proper hosting conditions for body liquids and tissues with a broad range of properties [3-7]. Fuhrer et al. [3] produce 3D glassy carbon scaffolds by pyrolysis for culturing neural stem cells (NSCs). The successful cultivation of NSCs were proven by magnetic resonance imaging. Glassy carbon acted as an electrode material, which is able to provide electrical stimulus to the cells. Patel et al. [4] describe, that carbon nanotube carpets facilitating myoblast, which are precursors for later muscle cell differentiation, adhesion. As reported by Eivazzadeh-Keihan et al. [5], graphene and graphene oxide (GO) attract the attention of medical experts in bone regeneration and other fields of tissue engineering, because GO in polymer matrix provides a positive stimulus on the bone mineralization process. Diamond is known as a biointert material. Stankova et al. [6] were reinforcing polymeric scaffolds with diamond nanoparticles. They point out the cell behavior on diamond nanoparticle loaded scaffolds is markedly influences by the origin and the properties of the diamond nanoparticles. Another application for carbon are nanodots, which could provide guidance for other molecules. In this context, Ngu-Schwemlein et al. [7] suggest carbon nanodot scaffolds for facilitating the rational design of antimicrobial materials for reducing the antibiotic resistance. Diamond-like coatings and carbon-based films provide low friction in artificial joints, if the microstructure and adherence are properly adjusted [8-10]. In addition, there are indications, that hydrogenated diamond-like carbon coatings favor protein adherence [11].

In the present study, tribological behavior of amorphous carbon-hydrogen coatings on medical grade CoCrMo-substrates with and without hyaluronic gel as intermediate medium are compared at different parameters. High normal loads are applied in order to prove the limits and damage phenomena of such coating. In practical applications, not only high or asymmetrical loading occur due to tilting, loosening, displacement, and dislocation of implants [12-14], but also during sudden start-stop situations or jumping of the patient.

\section{Materials and Methods}

\section{1. a-C:H Deposition}

In this study, an a-C:H coating with $60 \% \mathrm{sp}^{3}$ hybridized C-C bonds and a thickness of $2.5 \mu \mathrm{m}$ is applied. The amorphous carbon-hydrogen coating deposition were performed by plasma enhanced chemical vapor deposition (PE-CVD). Following evacuation of the chamber and krypton inert gas flushing, gaseous precursor benzene is fed into the plasma chamber. Ionization of the benzene occurred due to plasma generation by direct current discharge.

The plasma was ignited due to the voltage between hot cathode and anode grit (Figure 1) in the stage of inert gas flushing with krypton. The $\mathrm{Kr}$ gas pressure was $5 \times 10^{-4} \mathrm{~Pa}$. Stepwise, the noble gas was substituted by the hydrocarbon precursor, while the electrical parameters were adjusted gradually. The working pressure can be modified between $0.007 \mathrm{~Pa}$ and $10^{-4} \mathrm{~Pa}$. The electric parameters are summarized in Table 1. 
The carbon, carbon-hydrogen and other electrical charged species are attracted by the negative biased CoCrMo-substrate. They generate an a-C:H coating with certain fractions of $\mathrm{sp}^{3}$-hybridized and $\mathrm{sp}^{2}$-hybridized C-C-bonds as well as $\mathrm{C}-\mathrm{H}$-bonds and inclusion of atomic hydrogen.

Benzene is an aromatic hydrocarbon with the formula $\mathrm{C}_{6} \mathrm{H}_{6}$. As benzene is toxic, special regulations were fulfilled while handling with this hydrocarbon. The six carbon atoms of benzene arrange a ring. This ring-like six-fold carbons in benzene molecules already act as a scaffold for aromatic fractions in the later diamond-like carbon structure. Although the gaseous precursor is decomposed and ionized in the plasma, the structure of the precursor gas matters and is influencing the later diamond-like carbon nanostructure [15].

Excellent adherence of the a-C:H coatings is provided by a plasma etching of remaining impurities and gradual structural a-C:H adaptation due to changes in the deposition parameters and the composition of the gaseous precursor. The coatings' adherence meets the requirements of class HF1 of VDI standard 3198. It needs to be taken into consideration, that the substrate is medical grade CoCrMo and no hardened steel with minimum 54 HRC.

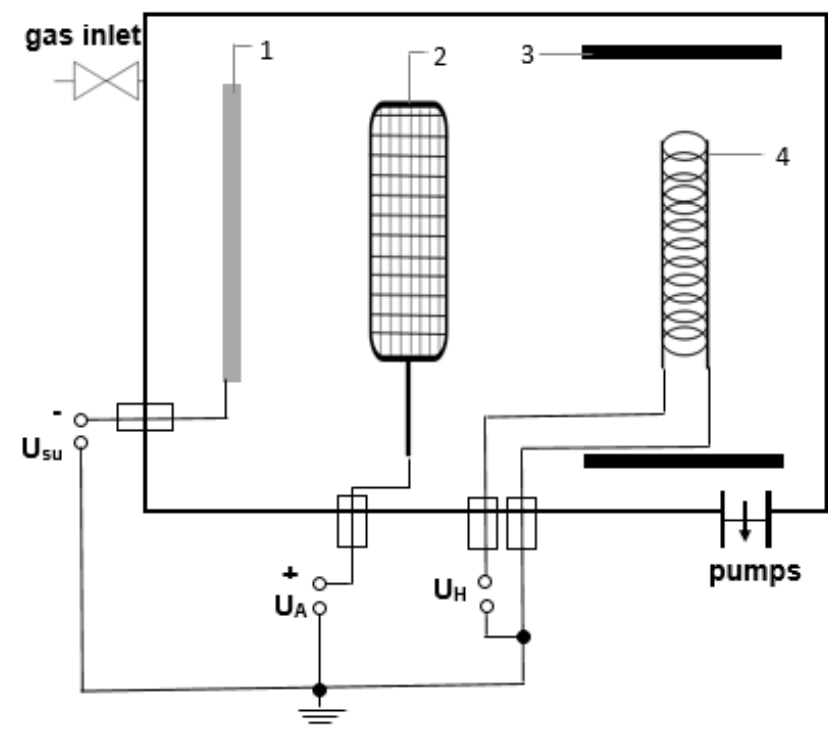

1 substrate holder

2 anode grid

3 radiation screen

4 hot cathode

Figure 1. Schematic of the set-up for a-C:H deposition by direct current discharge.

Table 1. Processing parameters for diamond-like carbon coatings deposition

\begin{tabular}{cc}
\hline Electric Parameters & \\
\hline Hot cathode heating current $\mathrm{U}_{\mathrm{H}}$ & $30-80 \mathrm{~A}$ \\
Discharge current & $0.1-1 \mathrm{~A}$ \\
Current through substrate holder & $10-400 \mathrm{~mA}$ \\
Voltage between cathode and anode grid & $30-300 \mathrm{~V}$ \\
Bias voltage & $0-3.5 \mathrm{kV}$ \\
\hline
\end{tabular}

\subsection{Tribological Tests}

Tribological tests were carried out with the translatory oscillation apparatus of the company Optimol GmbH, Munich, Germany. It is designed to testify liquid and consistent lubricants, as well as solid lubricants and coatings by applying standardized conditions (DIN EN ISO 51834 parts 1, 2, and 3).

During each wear test, a zirconia ball with a diameter of $10 \mathrm{~mm}$ was moved across the surface of the disc sample. The $\mathrm{ZrO}_{2}$ type was yttria stabilized zirconia with $5 \% \mathrm{Y}_{2} \mathrm{O}_{3}$. As summarized in Table 2, a normal force $\mathrm{F}_{\mathrm{n}}$ of $100 \mathrm{~N}$ was applied. In the standardized test apparatus, the zirconia ball is screwed down in the upper holder (Figure 2). It cannot roll, but slides across the surface of the disc sample. Before the test, balls and samples were cleaned with ethanol. For the sliding stroke of $1 \mathrm{~mm}$ 
two different frequencies, $1 \mathrm{~Hz}$ or $50 \mathrm{~Hz}$, were selected. The relative humidity RH stayed between $15.2 \%$ and $16.4 \%$ in the laboratory during the wear tests.

Table 2. Parameters of the wear tests

\begin{tabular}{cccccc}
\hline Disc & Ball & $\begin{array}{c}\text { Intermediate } \\
\text { Medium }\end{array}$ & $\begin{array}{c}\text { Normal Force } \\
\mathbf{F}_{\mathbf{n}} \mathbf{( N )}\end{array}$ & $\begin{array}{c}\text { Frequency } \\
\mathbf{( H z )}\end{array}$ & Time (s) \\
\hline CoCrMo & $\mathrm{ZrO}_{2}$ & dry & 100 & 1 & 1800 \\
CoCrMo(a-C:H) & $\mathrm{ZrO}_{2}$ & dry & 100 & 1 & 1800 \\
CoCrMo & $\mathrm{ZrO}_{2}$ & hyaluronic gel & 100 & 1 & 1800 \\
CoCrMo(a-C:H) & $\mathrm{ZrO}_{2}$ & hyaluronic gel & 100 & 1 & 1800 \\
CoCrMo & $\mathrm{ZrO}_{2}$ & dry & 100 & 50 & 1800 \\
CoCrMo(a-C:H) & $\mathrm{ZrO}_{2}$ & dry & 100 & 50 & 1800 \\
CoCrMo & $\mathrm{ZrO}_{2}$ & hyaluronic gel & 100 & 50 & 1800 \\
CoCrMo(a-C:H) & $\mathrm{ZrO}_{2}$ & hyaluronic gel & 100 & 50 & 1800 \\
\hline
\end{tabular}

dry: without intermediate medium.

In the present study, a solid lubricant, the a-C:H coating, and a liquid lubricant-hyaluronic gel-were investigated separately and in combination. The hyaluronic gel is composed of aqua, sodium hyaluronate, creatine acetyl, hexapeptide- 8 , sodium benzoate, and citric acid. As the relative humidity in the laboratory was relatively low, the tests without hyaluronic gel are named as 'dry' (Figure 3a). After immersion of the ball in viscous hyaluronic gel, it forms a meniscus between the ball and the disc (Figure $3 b$ ).There was an excellent wetting between hyaluronic gel and solids observed the hyaluronic gel meniscus remained intact for the whole test duration of $30 \mathrm{~min}$.

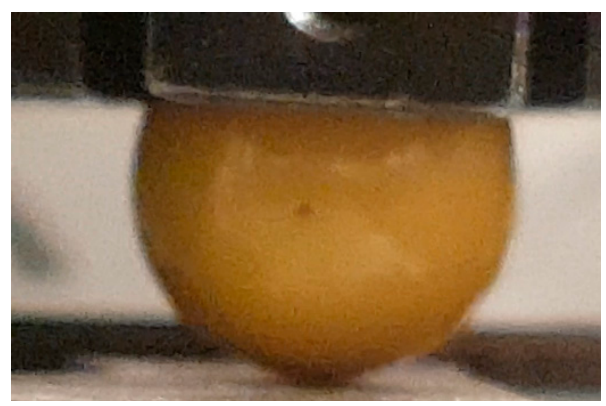

Figure 2. Sliding $\mathrm{ZrO}_{2}$ ball moves across CoCrMo sample with $1 \mathrm{~Hz}$.

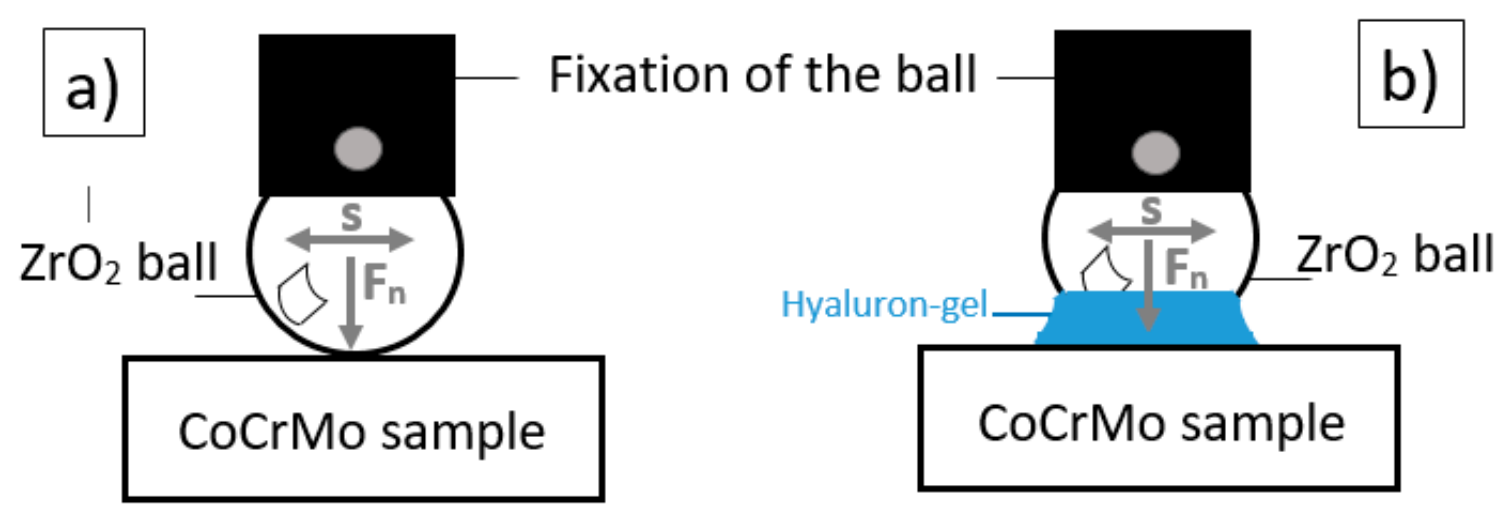

Figure 3. Schematic of the test set up: (a) without hyaluronic gel (dry); (b) with hyaluronic gel $F_{n}$ : normal load; s: sliding distance (stroke).

The wear volume was calculated according the standard DIN 51834-1. The cross-sectional area in the middle of the wear trace of the disc $W_{\mathrm{q} \text {, disc }}$ (Figure 4) were measured with the digital microscope 
KEYENCE VHX 950F (see Section 2.5). Standard DIN 51834-1 states Equations (1) and (2) for calculating the volumetric wear of the ball or the volumetric wear of the disc. Both equations were applied for calculation of the volumetric wear data in present study.

$$
\begin{gathered}
W_{V, \text { ball }}=\frac{\pi \cdot d_{1}^{2} \cdot d_{2}^{2}}{64}\left(\frac{1}{R}-\frac{1}{r}\right) \\
W_{V, \text { disc }}=\frac{\pi \cdot d_{4}^{2} \cdot\left(d_{3}-s\right)^{2}}{64} \cdot \frac{1}{r}+s \cdot W_{q, \text { disc }}
\end{gathered}
$$

$\mathrm{W}_{\mathrm{v}, \text { ball }}$ : volumetric wear of the ball

$\mathrm{W}_{\mathrm{v} \text {,disc }}$ : volumetric wear of the disc

$\mathrm{W}_{\mathrm{q} \text {,disc }}$ : cross-sectional area of the wear trace of the disc perpendicular to the sliding direction (measured in the middle of the wear trace)

s: stroke

$\mathrm{d}_{1}$ : diameter of the wear trace in the ball parallel to the sliding direction

$\mathrm{d}_{2}$ : diameter of the wear trace in the ball perpendicular to the sliding direction

$\mathrm{d}_{3}$ : diameter of the wear trace in the disc parallel to the sliding direction

$\mathrm{d}_{4}$ : diameter of the wear trace in the disc perpendicular to the sliding direction

$\mathrm{R}$ : radius of the ball in $\mathrm{mm}$

r: average radius of the wear trace of the ball after the test (can be calculated according Equation (3))

$$
r=\frac{d_{2}^{3}}{12 W_{q, \text { disc }}}
$$

\section{(a)}

(b)

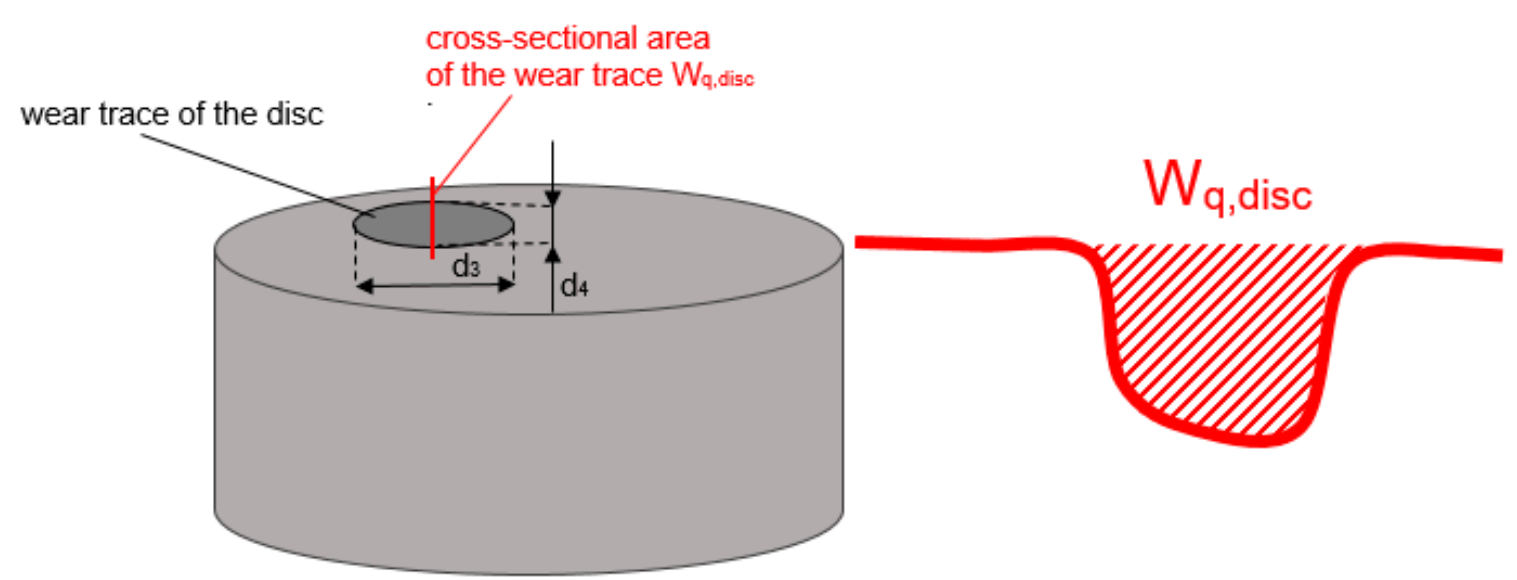

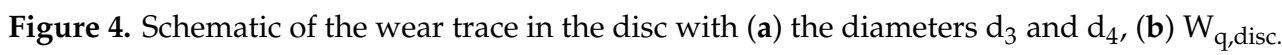

\subsection{Raman Spectroscopy}

Raman spectra were acquired with the Renishaw system inVia QTT5394 equipment (Renishaw $\mathrm{GmbH}$, Deutschland). The excitation volume of the Nd:YAG laser, which operated at a wavelength of $532 \mathrm{~nm}$ and $0.5 \mathrm{~mW}$, is large. It exceeds more than 10-15 nm. Raman shifts were measured over a wavenumber range from 500 to $3000 \mathrm{~cm}^{-1}$ by applying 20 accumulations for each measurement. Baseline correction were applied to all spectra to remove small fluorescence/luminescent background. The C-C vibrations inside selected wear traces and at the edges of them were recorded. Automatic curve fittings were performed with the Renishaw wire4.2 software. 


\subsection{Scanning Electron Microscopy (SEM)}

Information about the surface topography and composition was possible due to ZEISS EVO MA15 Field Emission Scanning Electron Microscopy. The images were recorded using the detection mode of secondary electrons. Zeiss EVO MA15 SEM safeguards data quality on hydrated and heavily contaminated samples, by allowing these samples to remain in their native state. Because in some cases of the present study, hyaluronic gel or wear products remained at the surface after wear test, the choice of this SEM equipment was appropriate. An acceleration voltage of $15 \mathrm{kV}$ were chosen for the electrons, and, secondary electron detector was placed at a working distance of $9 \mathrm{~mm}$.

\subsection{Digital Microscopy}

The design of the digital microscope VHX 950F (KEYENCE GmbH, Deutschland) allows high-resolution and large depth-of-field imaging. A general advantage of digital microscopy is the achievement of a fully focused image of topographies and uneven surfaces in a short time. The z-axis motorized stage allows stitching of single photos, which can be added to form a 3D image of the object. The minimal displacement in $z$-direction is $200 \mathrm{~nm}$. With the possible magnification range of 100 to 1000 times, the KEYENCE VHX 950F enables a wide range of observation from macro-scale stereoscopic imaging to the detailed analysis of an SEM.

\section{Results}

\subsection{Coefficient of Friction $\mathrm{COF}$}

For $\mathrm{ZrO}_{2}$ ball sliding against the medical grade $\mathrm{CoCrMo}$ alloy with $1 \mathrm{~Hz}$, the maximum coefficient of friction is 0.482. After an initial increase, COF curve (Figure 5) remains around a certain level, but shows fluctuations and an unsteady characteristic. Increasing the velocity of the sliding movement up to $50 \mathrm{~Hz}$ leads to a steady growing COF reaching tremendous COF values higher than 0.7 at the end of the test.

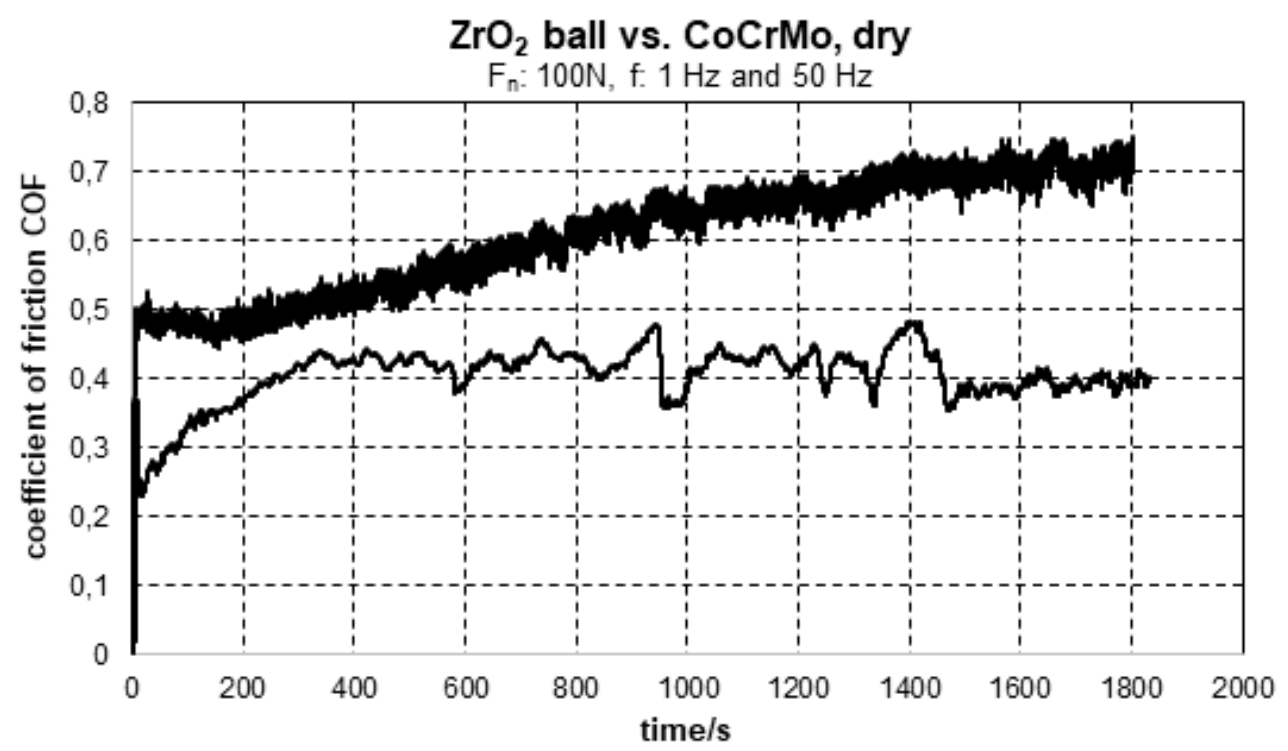

Figure 5. Coefficient of friction COF during the dry sliding of $\mathrm{ZrO}_{2}$ ball against uncoated CoCrMo with $50 \mathrm{~Hz}$ or $1 \mathrm{~Hz}\left(\mathrm{~F}_{\mathrm{n}}: 100 \mathrm{~N}\right)$.

For biomaterials, $50 \mathrm{~Hz}$ are excessive loading conditions, while $1 \mathrm{~Hz}$ is equal to a fast-moving velocity. The $50 \mathrm{~Hz}$ should reflect the overload case of the biomaterial pairing. As seen from Figure 6, the temperature increase is higher for the high frequency loading. 


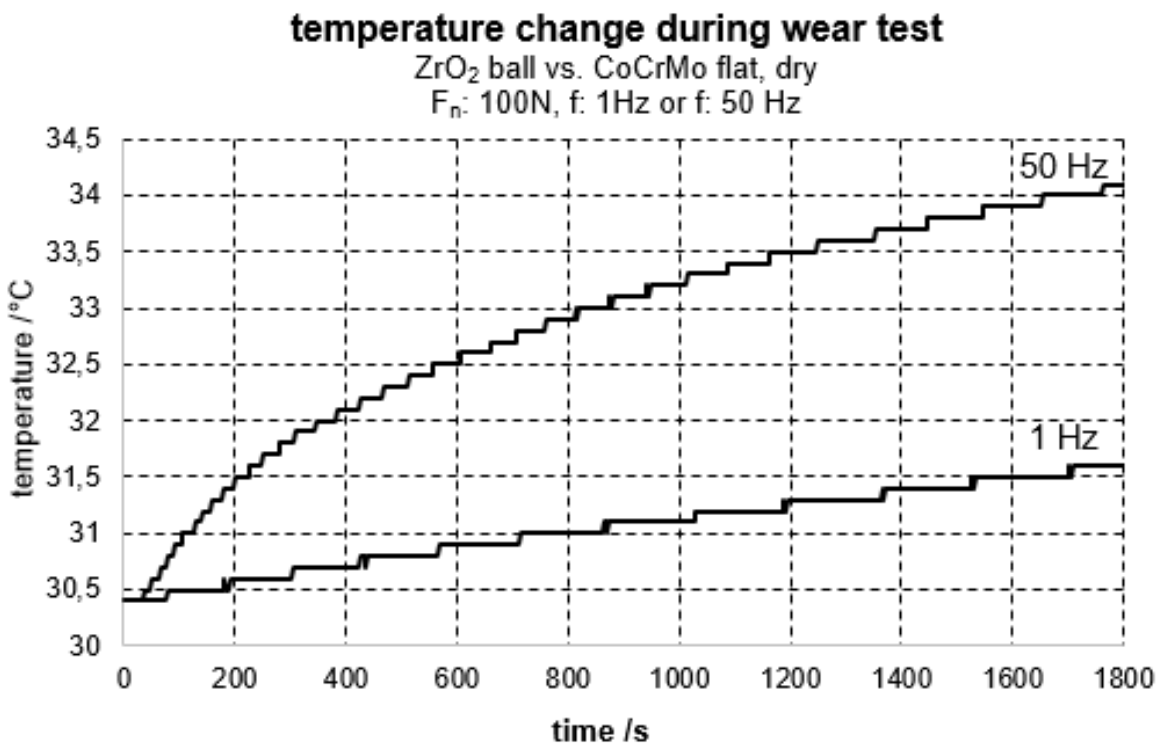

Figure 6. Temperature change during the dry sliding of $\mathrm{ZrO}_{2}$ ball against uncoated CoCrMo with $50 \mathrm{~Hz}$ or $1 \mathrm{~Hz}\left(\mathrm{~F}_{\mathrm{n}}: 100 \mathrm{~N}\right)$.

An a-C:H coating on the CoCrMo surface effects a minor reduction of the COF in the extreme overload case of $50 \mathrm{~Hz}$. After $15 \mathrm{~min}$, the $\mathrm{COF}_{15}$ is 0.466 for zirconia sliding against the a-C:H coated CoCrMo under dry conditions (Table 3). It reaches the level of the low frequency case of sliding with $\mathrm{ZrO}_{2}$ ball against the uncoated CoCrMo disc approximately. It amounts to 0.552 at the end of the test. If the hyaluronic gel acts as intermediate lubricant, the COF remains below 0.1 at first (Figure 7, colored curve), but reaches a $\mathrm{COF}_{30}$ of 0.445 and $\mathrm{COF}_{\max }$ of 0.549 (Table 3). Under the impact of $100 \mathrm{~N}$ normal load but slow movement of $1 \mathrm{~Hz}$, the dry sliding of the $\mathrm{ZrO}_{2}$ ball against the DLC coated CoCrMo is accompanied by an initial tremendous increase of COF up to 0.369 .

$\mathrm{ZrO}_{2}$ ball vs. $\mathrm{CoCrMo}(\mathrm{a}-\mathrm{C}: \mathrm{H})$ disc

$\mathrm{F}_{\mathrm{n}}: 100 \mathrm{~N}$, f: $50 \mathrm{~Hz}$, (a) dry, (b) hyaluronic gel

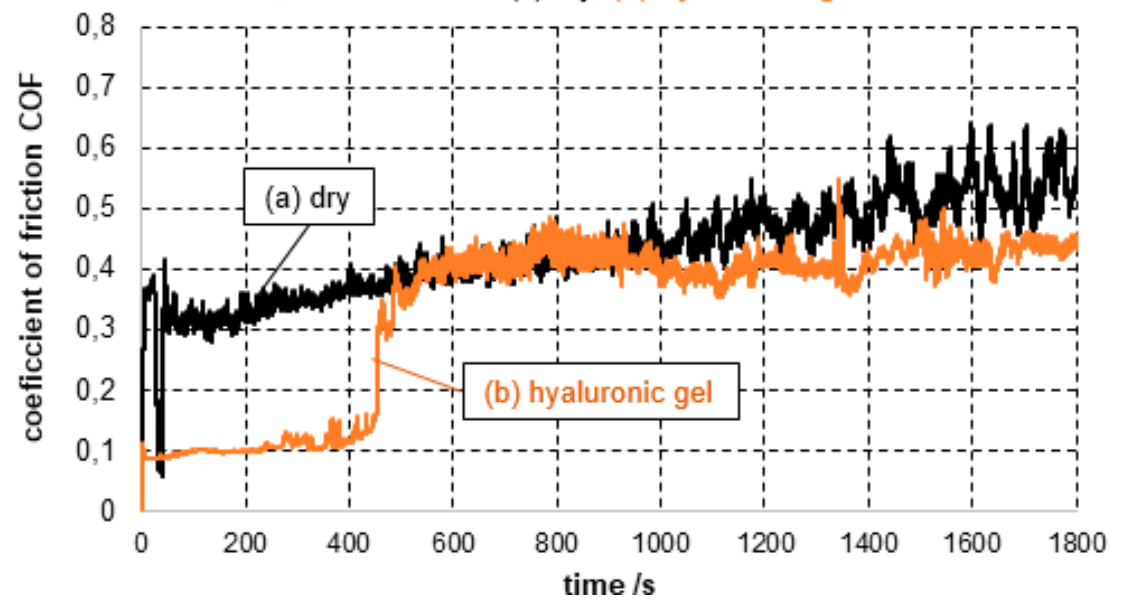

Figure 7. Coefficient of friction COF during the sliding of $\mathrm{ZrO}_{2}$ ball against a-C:H coated CoCrMo without and with hyaluronic gel lubrication $\left(\mathrm{F}_{\mathrm{n}}: 100 \mathrm{~N}, \mathrm{f}: 50 \mathrm{~Hz}\right)$. 
Table 3. Coefficients of friction

\begin{tabular}{ccccccc}
\hline Disc & Ball & $\begin{array}{c}\text { Intermediate } \\
\text { Medium }\end{array}$ & $\mathbf{f ~ ( H z )}$ & $\mathbf{C O F}_{\text {max }}$ & $\mathbf{C O F}_{\mathbf{1 5}}$ & $\mathbf{C O F}_{\mathbf{3 0}}$ \\
\hline CoCrMo & $\mathrm{ZrO}_{2}$ & dry & 1 & 0.482 & 0.438 & 0.394 \\
CoCrMo(a-C:H) & $\mathrm{ZrO}_{2}$ & dry & 1 & 0.369 & 0.113 & 0.105 \\
CoCrMo & $\mathrm{ZrO}_{2}$ & hyaluronic gel & 1 & 0.401 & 0.308 & 0.204 \\
CoCrMo(a-C:H) & $\mathrm{ZrO}_{2}$ & hyaluronic gel & 1 & 0.137 & 0.096 & 0.105 \\
CoCrMo & $\mathrm{ZrO}_{2}$ & dry & 50 & 0.751 & 0.637 & 0.724 \\
CoCrMo(a-C:H) & $\mathrm{ZrO}_{2}$ & dry & 50 & 0.678 & 0.466 & 0.552 \\
CoCrMo & $\mathrm{ZrO}_{2}$ & hyaluronic gel & 50 & 0.733 & 0.310 & 0.277 \\
CoCrMo(a-C:H) & $\mathrm{ZrO}_{2}$ & hyaluronic gel & 50 & 0.549 & 0.433 & 0.445 \\
\hline
\end{tabular}

$\mathrm{COF}_{15}$ : coefficient of friction after 15 min sliding; $\mathrm{COF}_{30}$ : coefficient of friction after 30 min sliding; $\mathrm{COF}_{\max }$ : maximal coefficient of friction.

During the slow movement of $1 \mathrm{~Hz}$ frequency (1 step per second), the COF decreases and reaches a relatively low level of $\mathrm{COF}_{15} 0.113$ and $\mathrm{COF}_{30}$ 0.105. The curve progression for zirconia ball sliding against the a-C:H coated CoCrMo under dry conditions is smooth in comparison to the zirconia/CoCrMo couple without a-C:H carbon coating. However, there are sections with sharp spikes in the COF curve (Figure 8), if zirconia ball slides slowly against the a-C:H coated CoCrMo in dry atmosphere. If hyaluronic gel is applied as an intermediate medium between the $\mathrm{CoCrMo}(\mathrm{a}-\mathrm{C}: \mathrm{H})$ disc and the $\mathrm{ZrO}_{2}$ ball, the initial COF is lowest in this study. A minimum COF of 0.084 was measured, and, $\mathrm{COF}_{15}$ amounts to 0.096 (Table 3). However, after $30 \mathrm{~min}$ testing time, the COFs without and with hyaluronic gel lubrication in the sliding contact are similar and slightly above 0.1 at $1 \mathrm{~Hz}$ and $100 \mathrm{~N}$ normal load (Figure 9). Observing the macroscopic appearance of the tribological system during the sliding test, the impression of drying-out of hyaluronic gel lubricant arose. The smooth and elastic co-movement of the hyaluronic gel droplet, which embedded the wear couple completely before the test (Figure 10), became less with accumulation of test cycle numbers.

Due to the impact of the hyaluronic gel, the run-in phase of zirconia ball sliding against the a-C:H coated CoCrMo is not accompanied by tremendous initial increase of the COF. $\mathrm{COF}_{\max }$ reaches 0.137 . Following this initial run-in stage, the COF remains below 0.1 with a minimum of 0.081 , but increases steadily up to the level of zirconia sliding against DLC coated CoCrMo without hyaluronic gel, having exactly the same $\mathrm{COF}_{30}$ of 0.105 at the end of the wear test (Figure 9).

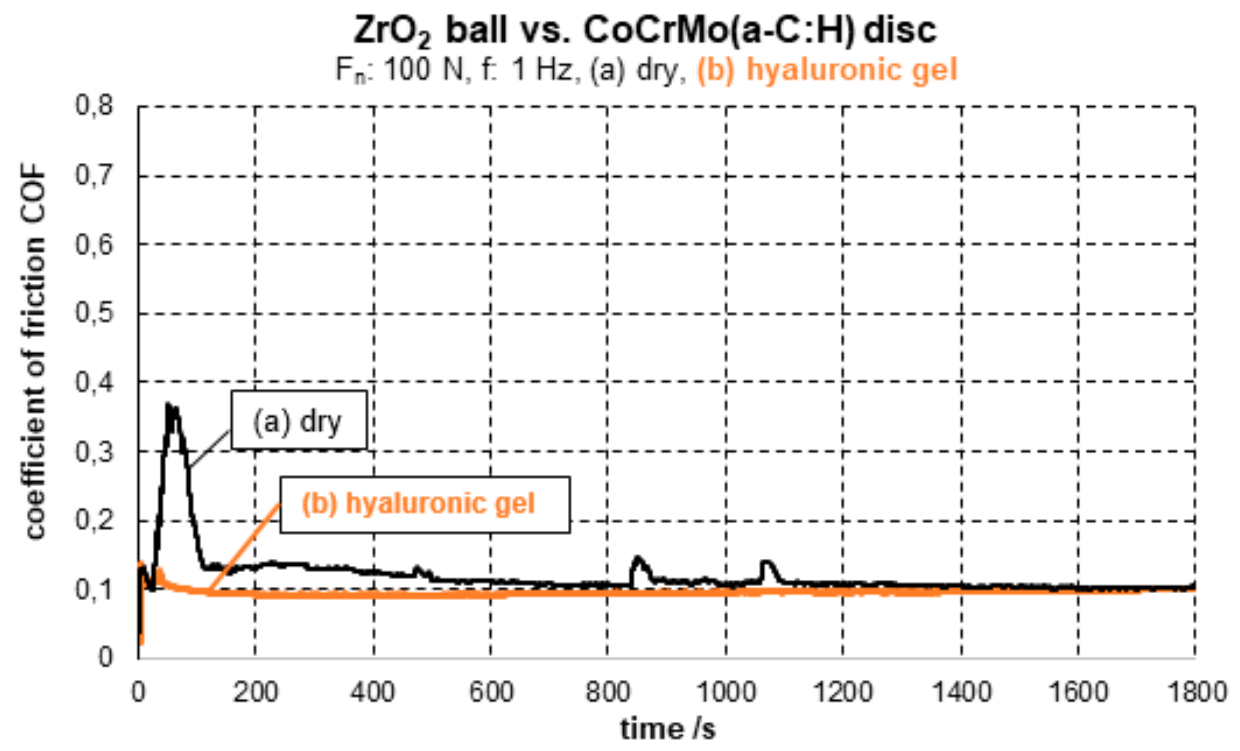

Figure 8. Coefficient of friction COF during the sliding of $\mathrm{ZrO}_{2}$ ball against a-C:H coated CoCrMo without and with hyaluronic gel lubrication $\left(\mathrm{F}_{\mathrm{n}}: 100 \mathrm{~N}, \mathrm{f}: 1 \mathrm{~Hz}\right)$. 
$\mathrm{ZrO}_{2}$ ball vs. $\mathrm{CoCrMo}(\mathrm{a}-\mathrm{C}: \mathrm{H})$ disc

$\mathrm{F}_{\mathrm{n}}: 100 \mathrm{~N}, \mathrm{f} .1 \mathrm{~Hz},(\mathrm{a}) \mathrm{dry},(\mathrm{b})$ hyaluronic gel

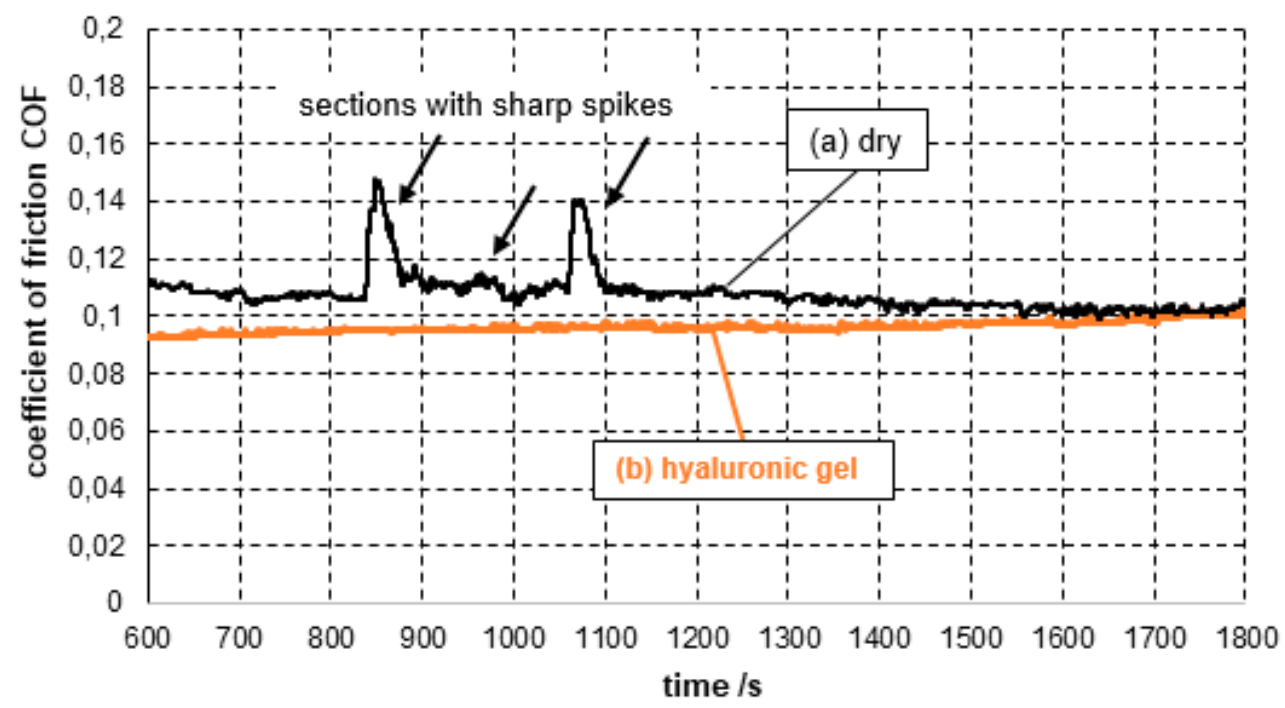

Figure 9. Section with sharp spikes sections in COF curve without hyaluronic gel lubrication (a), smooth COF curve with hyaluronic gel lubrication (b) during sliding of $\mathrm{ZrO}_{2}$ ball against $\mathrm{CoCrMo}(\mathrm{a}-\mathrm{C}: \mathrm{H})$ $\left(\mathrm{F}_{\mathrm{n}}: 100 \mathrm{~N}, \mathrm{f}: 1 \mathrm{~Hz}\right)$.

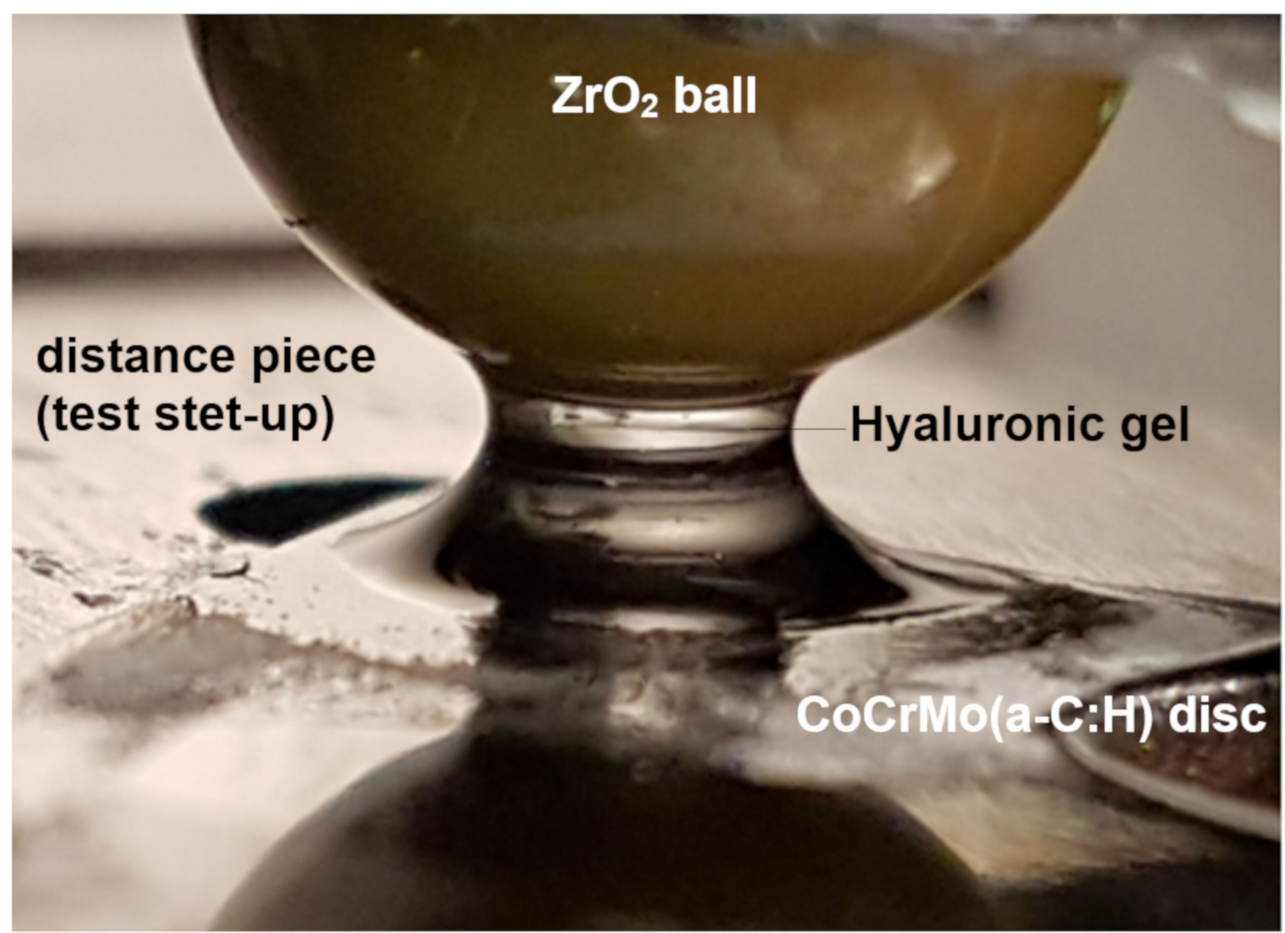

Figure 10. $\mathrm{ZrO}_{2}$ ball wetted with hyaluronic gel before the wear test of a-C:H coated CoCrMo sample with $1 \mathrm{~Hz}$.

\subsection{Wear Rates}

The hyaluronic gel reduces the wear rate of the DLC coated CoCrMo surfaces. If hyaluronic gel is applied as an intermediate medium, the wear rate of the $\operatorname{CoCrMo}(\mathrm{a}-\mathrm{C}: \mathrm{H})$ disc amounts to $0.16 \times 10^{-6} \mathrm{~mm}^{3} / \mathrm{N} \cdot \mathrm{m}$ (Table 4, Figure 11). By evaluating this wear rate, it is essential to take into consideration the low frequency of $1 \mathrm{~Hz}$ as well as the observed reduction in viscosity during the sliding of the zirconia ball. For higher frequency of $50 \mathrm{~Hz}$, the same tendencies like for low frequency 
sliding at $1 \mathrm{~Hz}$ can be observed for the wear rates of the disc (Table 4, Figure 12). The best results, which is the lowest wear rate is achieved for the a-C:H coated CoCrMo disc. However, the frequency influences the intensity of the wear. By applying the higher frequency of $50 \mathrm{~Hz}$, wear rates are increased. In the case of CoCrMo disc with an a-C:H coating and using hyaluronic gel lubrication, the $50 \mathrm{~Hz}$ sliding affects an approximately 3-fold higher wear in comparison to the $1 \mathrm{~Hz}$ sliding of the $\mathrm{ZrO}_{2}$ ball (Table 4, Figure 13).

The wear of the $\mathrm{ZrO}_{2}$ balls depends on the frequency as well (Table 4, Figures 14-16). For $1 \mathrm{~Hz}$ frequency, there was no wear of the $\mathrm{ZrO}_{2}$ ball observed. However, for $50 \mathrm{~Hz}$ frequency, a 3-fold higher wear of the ceramic $\mathrm{ZrO}_{2}$ ball in comparison to the pairing a-C:H coated disc was measured in hyaluronic gel (Figures 13 and 14). In general, the wear rates of the ceramic $\mathrm{ZrO}_{2}$ balls are lower in comparison to the discs. Only, the $\mathrm{ZrO}_{2}$ ball which slid against the CoCrMo(a-C:H) with $50 \mathrm{~Hz}$ und hyaluronic gel lubrication needs to be excluded from this trend.

It is expected that the contact situation affects boundary or mixed lubrication only. The dry sliding of the zirconia ball against the a-C:H coated CoCrMo disc results in a wear rate of a-C:H coated disc of $21.09 \times 10^{-6} \mathrm{~mm}^{3} / \mathrm{N} \cdot \mathrm{m}$ (Table 4 ), which is around two orders of magnitude higher in comparison to usage of hyaluronic gel as intermediate medium.

Table 4. Wear rates according the standard DIN 51834-3

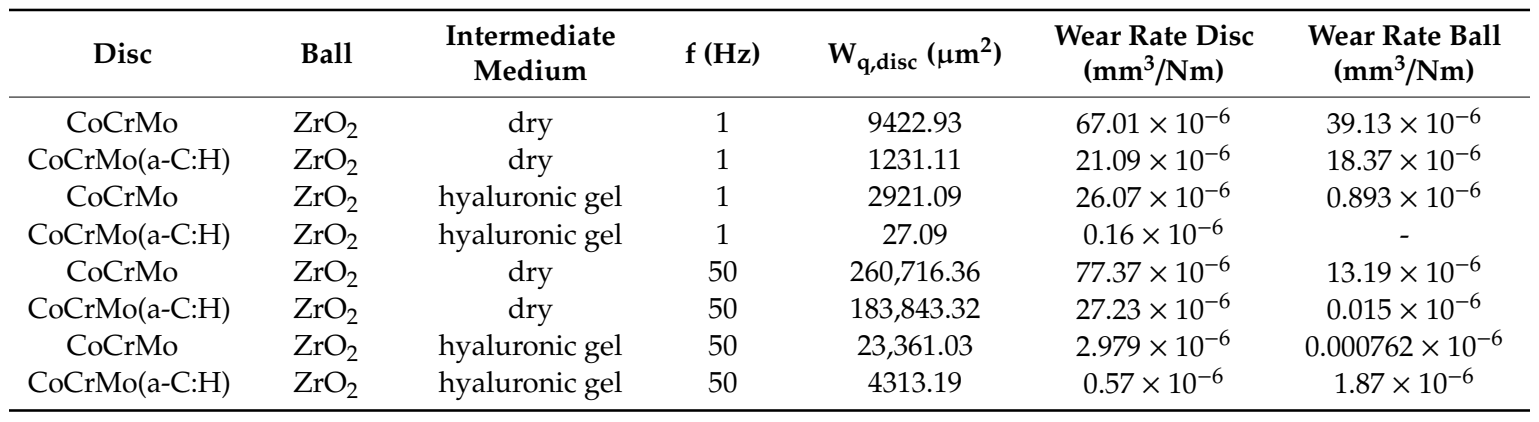

Wear rate disc

$\left(F_{\mathrm{n}}: 100 \mathrm{~N} ; \mathrm{f}: 1 \mathrm{~Hz}\right.$ )

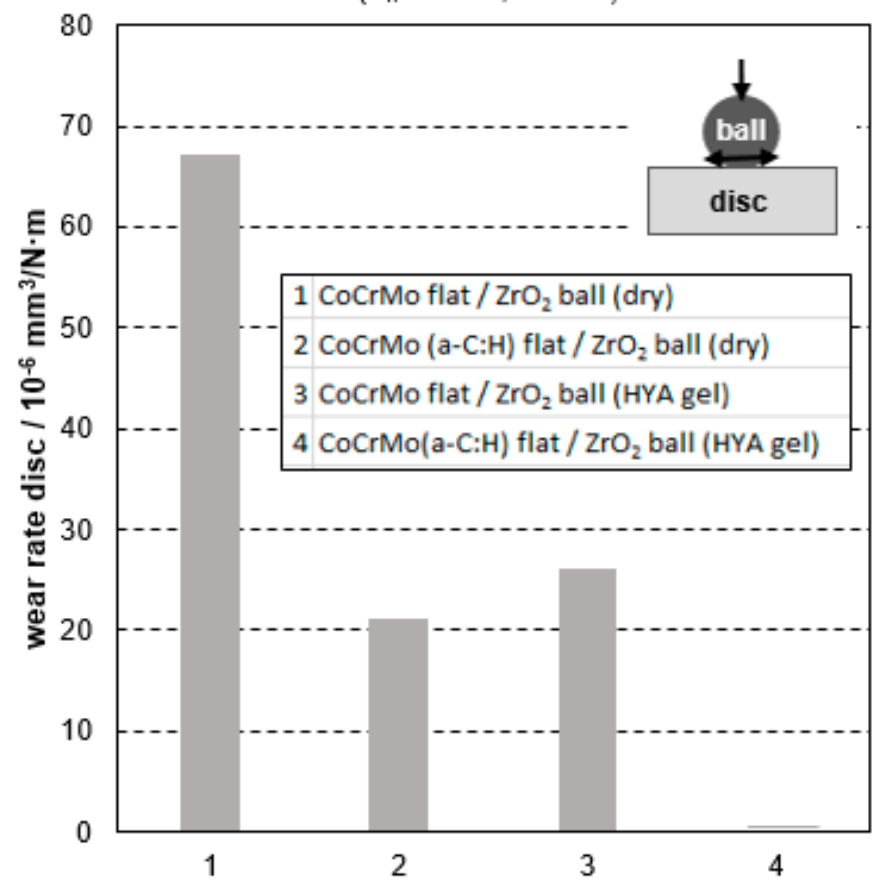

Figure 11. Wear of uncoated and a-C:H coated discs at $1 \mathrm{~Hz}$ frequency (dry or with hyaluronic gel lubrication). 


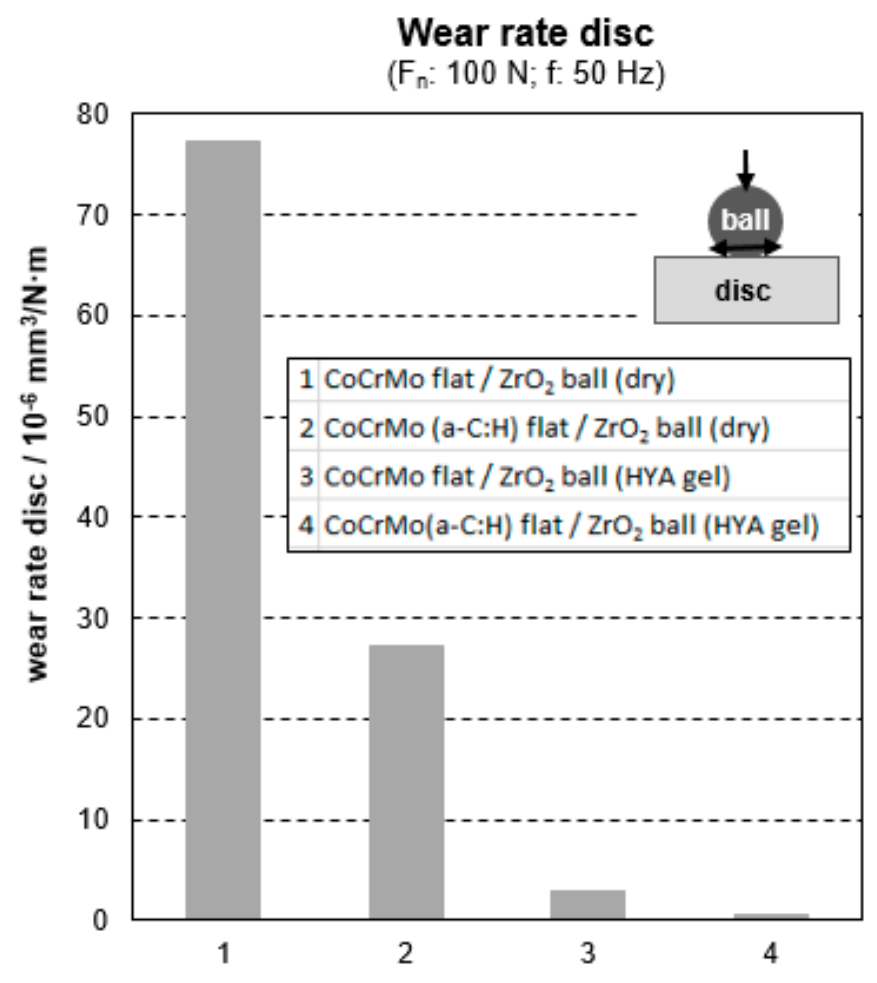

Figure 12. Wear of uncoated and a-C:H coated discs at $50 \mathrm{~Hz}$ frequency (dry or with hyaluronic gel lubrication).

\section{Wear rate ball: CoCrMo(a-C:H)}

$\left(F_{n}: 100 \mathrm{~N}\right.$, hyaluronic gel)

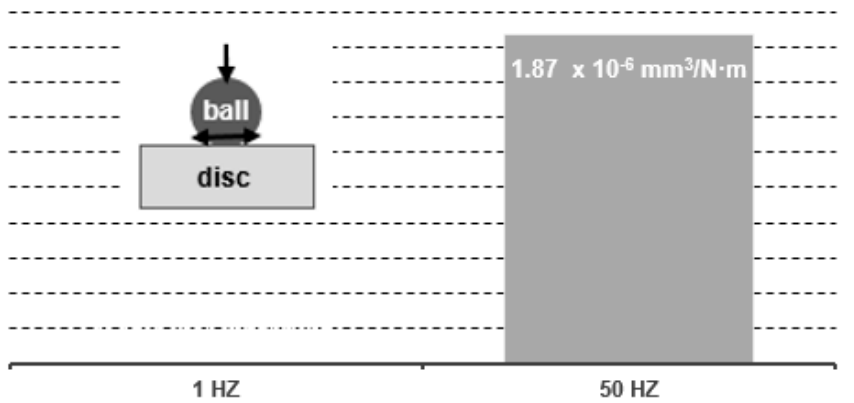

Figure 13. Wear of a-C:H coated discs at different frequencies.

\section{Wear rate disc: CoCrMo(a-C:H)}

$\left(\mathrm{F}_{\mathrm{n}}: 100 \mathrm{~N}\right.$, hyaluronic gel)

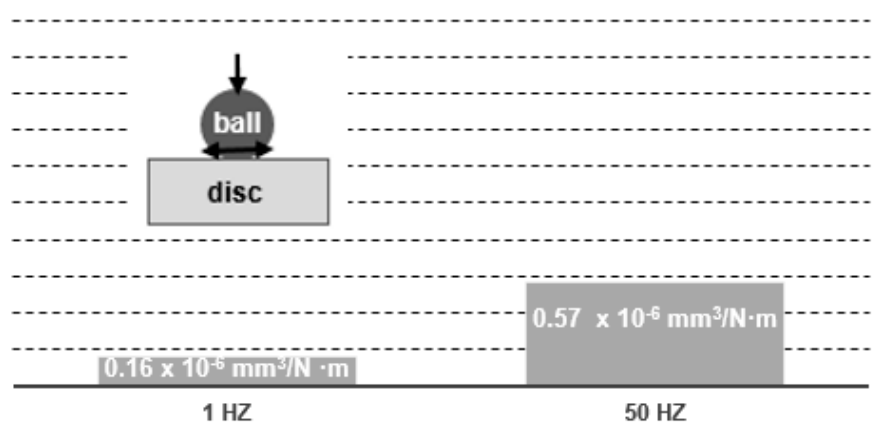

Figure 14. Wear of $\mathrm{ZrO}_{2}$ balls sliding against a-C:H coated discs at different frequencies. 
Wear rate ball

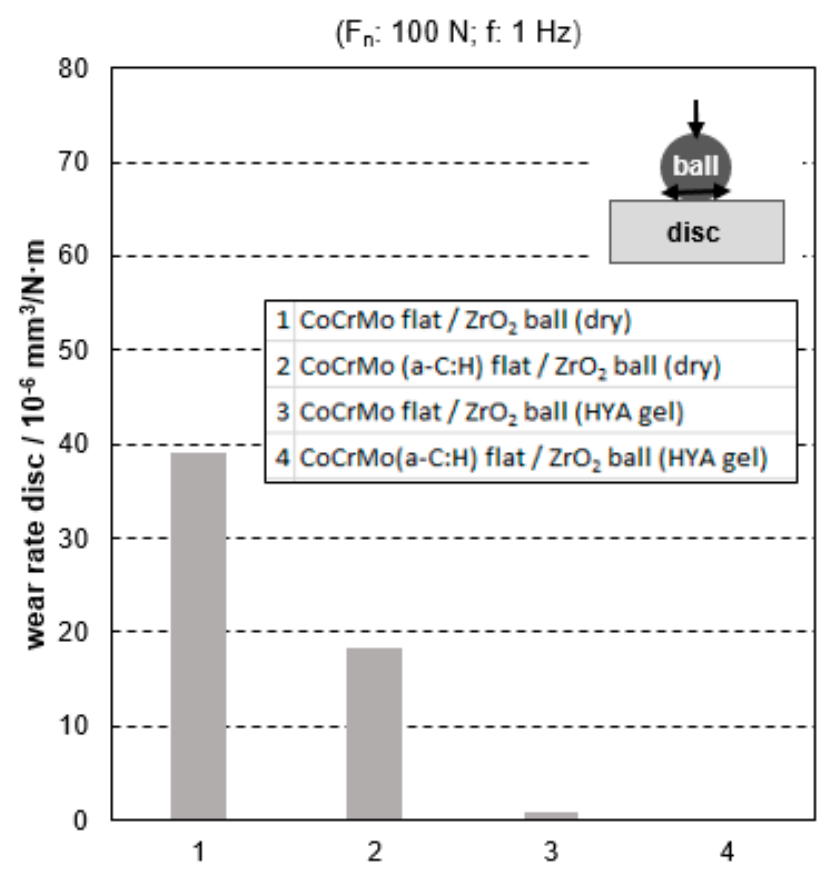

Figure 15. Wear of $\mathrm{ZrO}_{2}$ balls at $1 \mathrm{~Hz}$ frequency (dry or with hyaluronic gel lubrication).

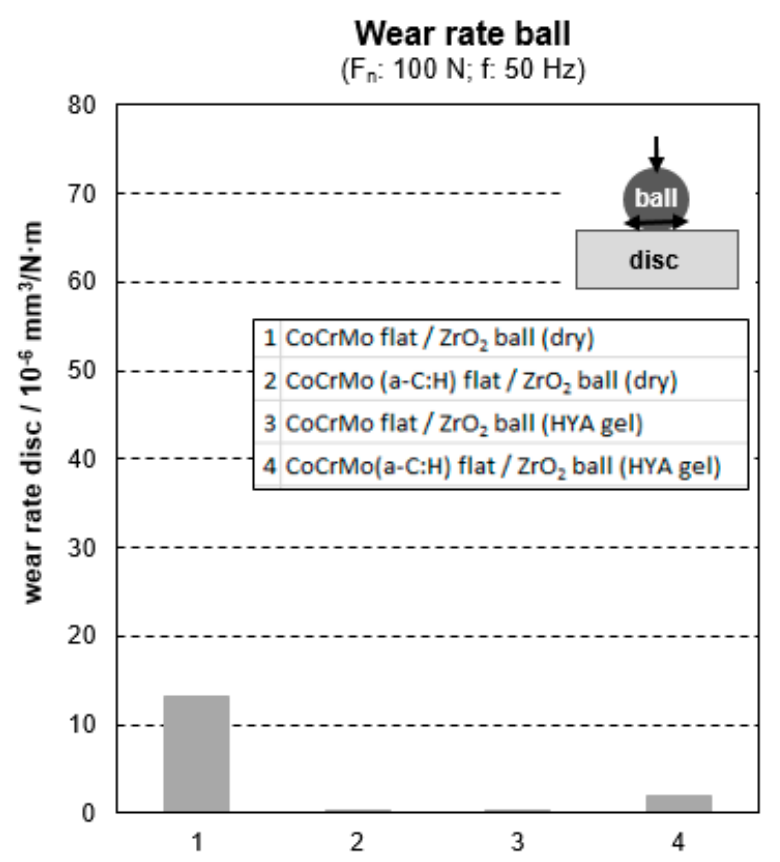

Figure 16. Wear of $\mathrm{ZrO}_{2}$ balls at $50 \mathrm{~Hz}$ frequency (dry or with hyaluronic gel lubrication).

\subsection{Microscopic Observations}

Figure 17a presents a digital image of the whole wear trace (Figure 17a) after dry sliding of $\mathrm{ZrO}_{2}$ ball against the DLC coated CoCrMo at $1 \mathrm{~Hz}$. Figure $17 \mathrm{~b}$ presents just the edge of this wear trace. Both photos give evidence of broken out segments within the contact zones. The deepness of the holes is some micrometers (Figure 17b) only, and with this value in the dimension of the DLC coating thickness.

SEM observations (Figure 18) show wrinkled and cracked a-C:H section nearby completely de-adhered a-C:H regions with exposed CoCrMo substrate surface. The metallic substrate obtains deep, but small and sharp grooves. They are not caused by the slow sliding movement of the $\mathrm{ZrO}_{2}$ 
ball, but seem to be effected by small and sharp segments of broken-out DLC fragments, which are now missing. The ductile CoCrMo seems to be plastic deformed by formerly pressed in a-C:H fragments. The a-C:H was not worn through, but cracked and broke out, as observed by SEM and digital microscopy (Figures 17 and 18). Looking at the remaining a-C:H coating, there is extensive cohesive failure too with cracking and shell-like breakouts. It strengthens the impression, that during the high normal load of $100 \mathrm{~N}$, the metallic CoCrMo substrate did not provide a sufficient support effect, but it was cyclic plastic deformed and forced the stiff inorganic carbon coating with considerably lower plastic deformability to crack.

The hyaluronic gel seems to buffer the insufficient supporting effect of the substrate. Although, the same normal force and frequency were applied, the a-C:H coating remains adhering. The wear trace just shows shearing of the a-C:H coating and minor wear grooves within the a-C:H which is good visible in the black and white digital image (Figure 19a). The colored digital image points to the fact, that there is a trace in the a-C:H visible due to the oriented grooves along the sliding direction. However, the highness level is similar to the roughness of the a-C:H surface. The SEM images show huge plastic deformed grooves for the CoCrMo substrate (Figure 20) and minor grooves within the a-C:H (Figure 21) after a sliding of the $\mathrm{ZrO}_{2}$ ball with $1 \mathrm{~Hz}$. It points to the fact, that the present a-C:H coating can be remodeled and deformed to a certain extent without breaking and cracking. The extent of damage tolerant behavior of different diamond-like carbon coatings depend on several nanostructural features, like hydrogen-content and bonding, $\mathrm{C}$-C-arrangement into aromatic rings or chains, C-C network density, or number and size of spaces in the amorphous carbon network. Other extraordinary influences are the extent of residual stresses, which depend on the ion energy [11] during film deposition as well as degree of ionization and other deposition parameters. As known, the ionization potential of different gaseous precursors for a-C:H generation [15] is different. Benzene has a low ionization potential of about $9 \mathrm{eV}$ only. In comparison to methane or ethane as precursor gases, it gives dense films due to a low $\mathrm{H}$ content of the precursor molecules, which effect a lower content of $\mathrm{H}$ in the resulting a-C:H films.

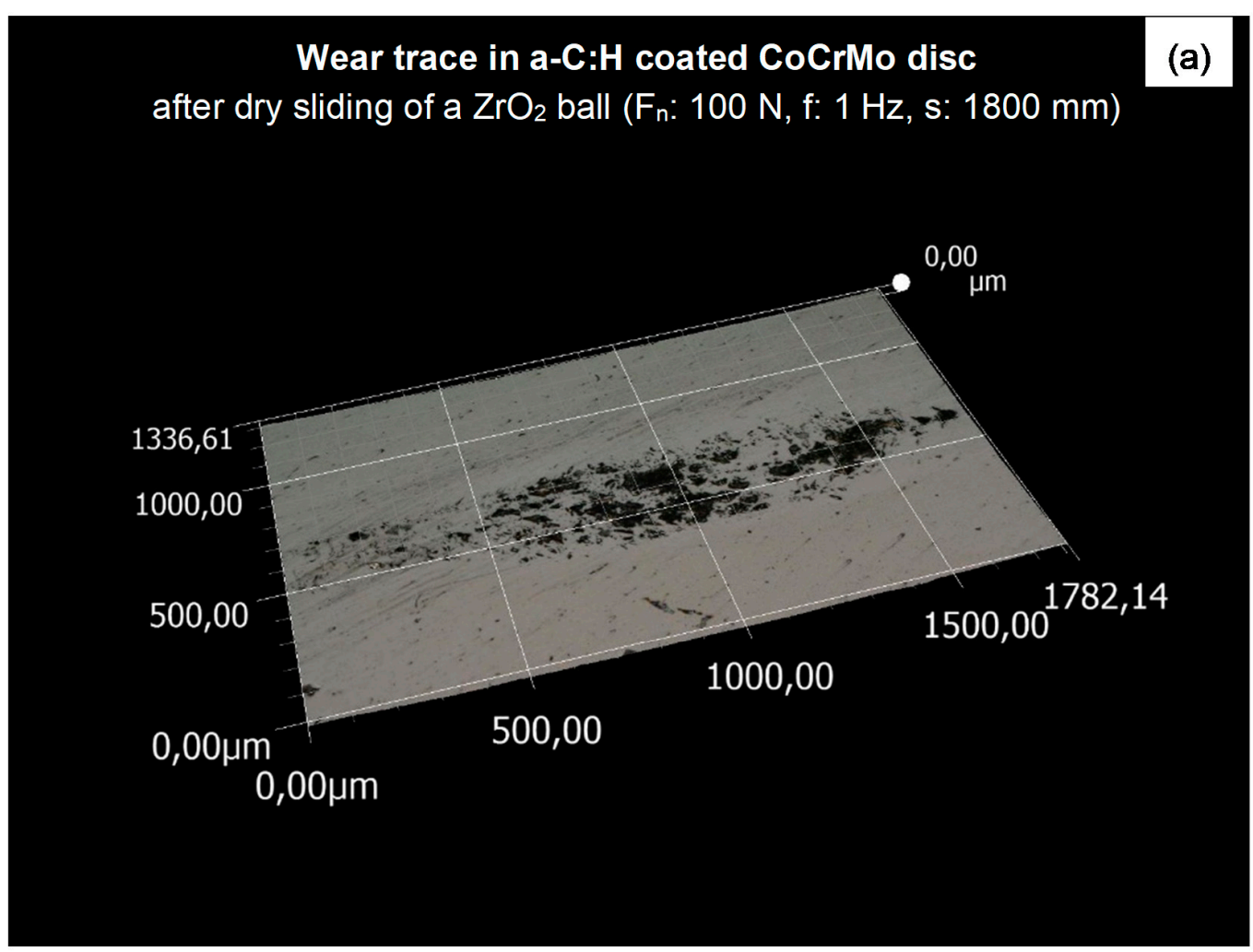

Figure 17. Cont. 


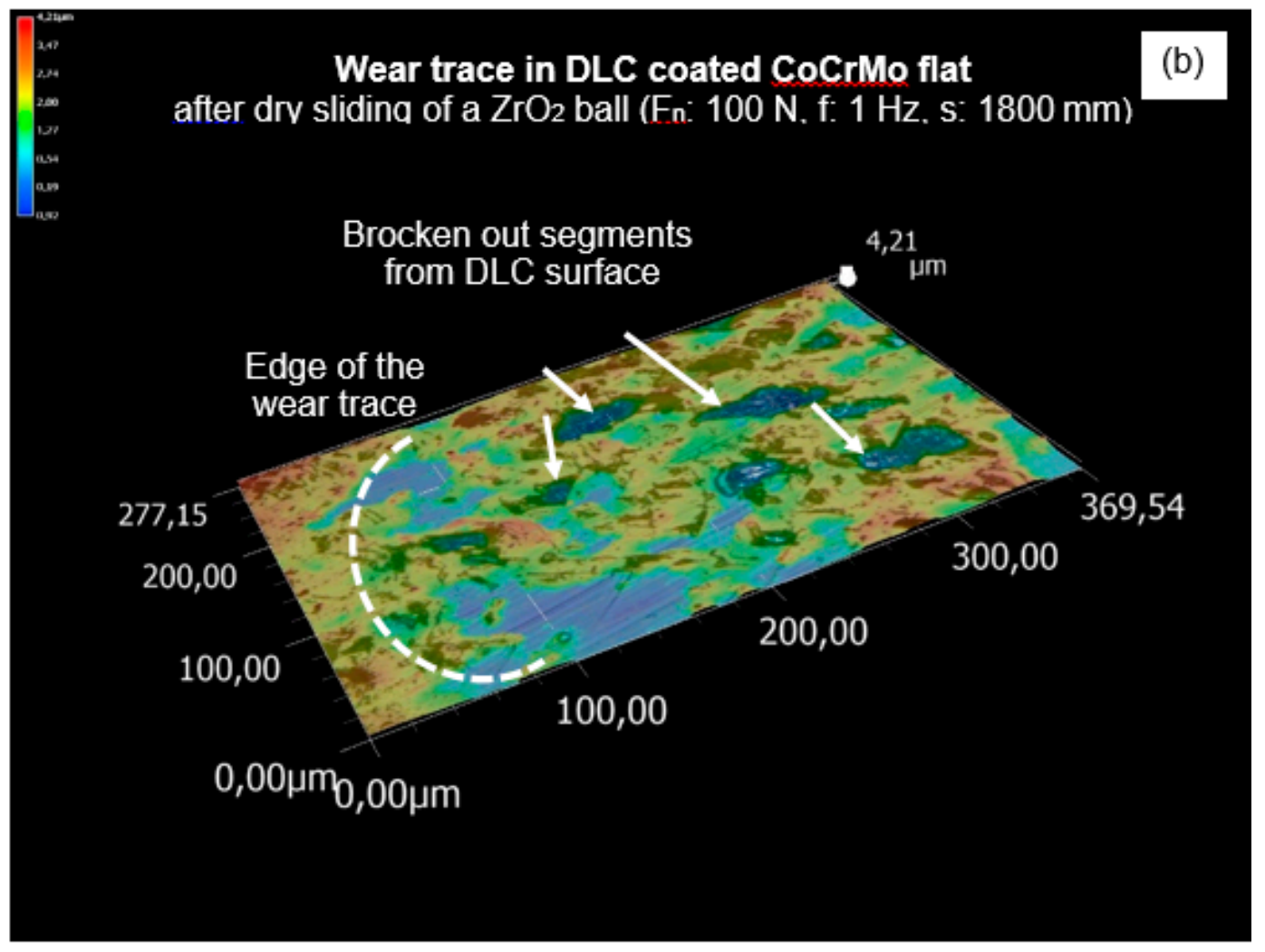

Figure 17. Wear trace after sliding of $\mathrm{ZrO}_{2}$ ball against a-C:H coated CoCrMo without hyaluronic gel lubrication (dry, $\left.\mathrm{F}_{\mathrm{n}}: 100 \mathrm{~N}, \mathrm{f}: 1 \mathrm{~Hz}\right)$; (a) overview of the wear trace; (b) edge of the wear trace.

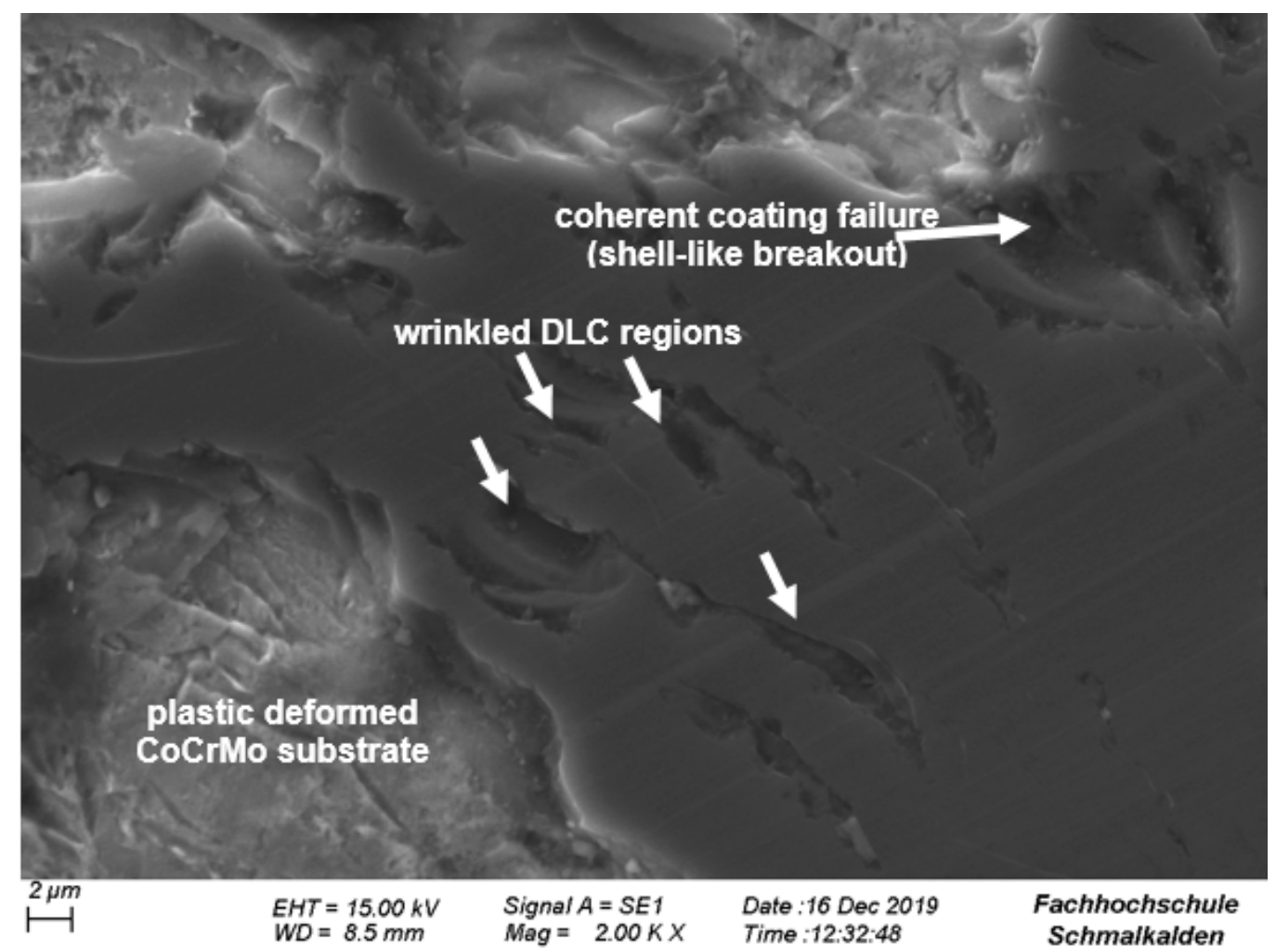

Figure 18. Wear trace with wrinkled hydrogenated a-C:H and coating deadherence after dry sliding of $\mathrm{ZrO}_{2}$ ball against the CoCrMo(a-C:H) disc $\left(\mathrm{F}_{\mathrm{n}}: 100 \mathrm{~N}\right.$, f: $\left.1 \mathrm{~Hz}\right)$, SEM. 

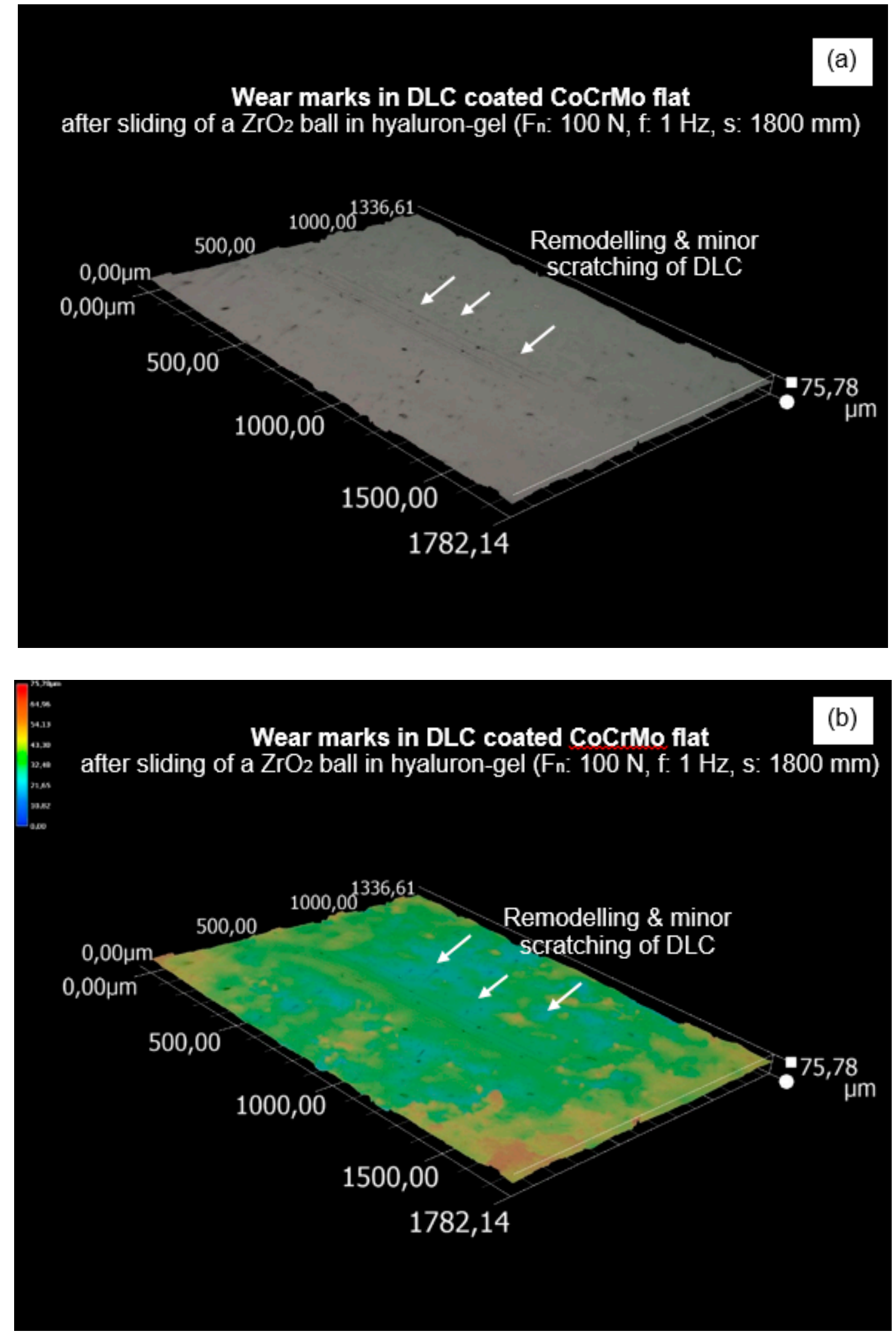

Figure 19. Wear trace after sliding of $\mathrm{ZrO}_{2}$ ball against a-C:H coated CoCrMo with hyaluronic gel lubrication (Fn: 100 N, f: $1 \mathrm{~Hz}$ ); (a) black and white image; (b) color image. 


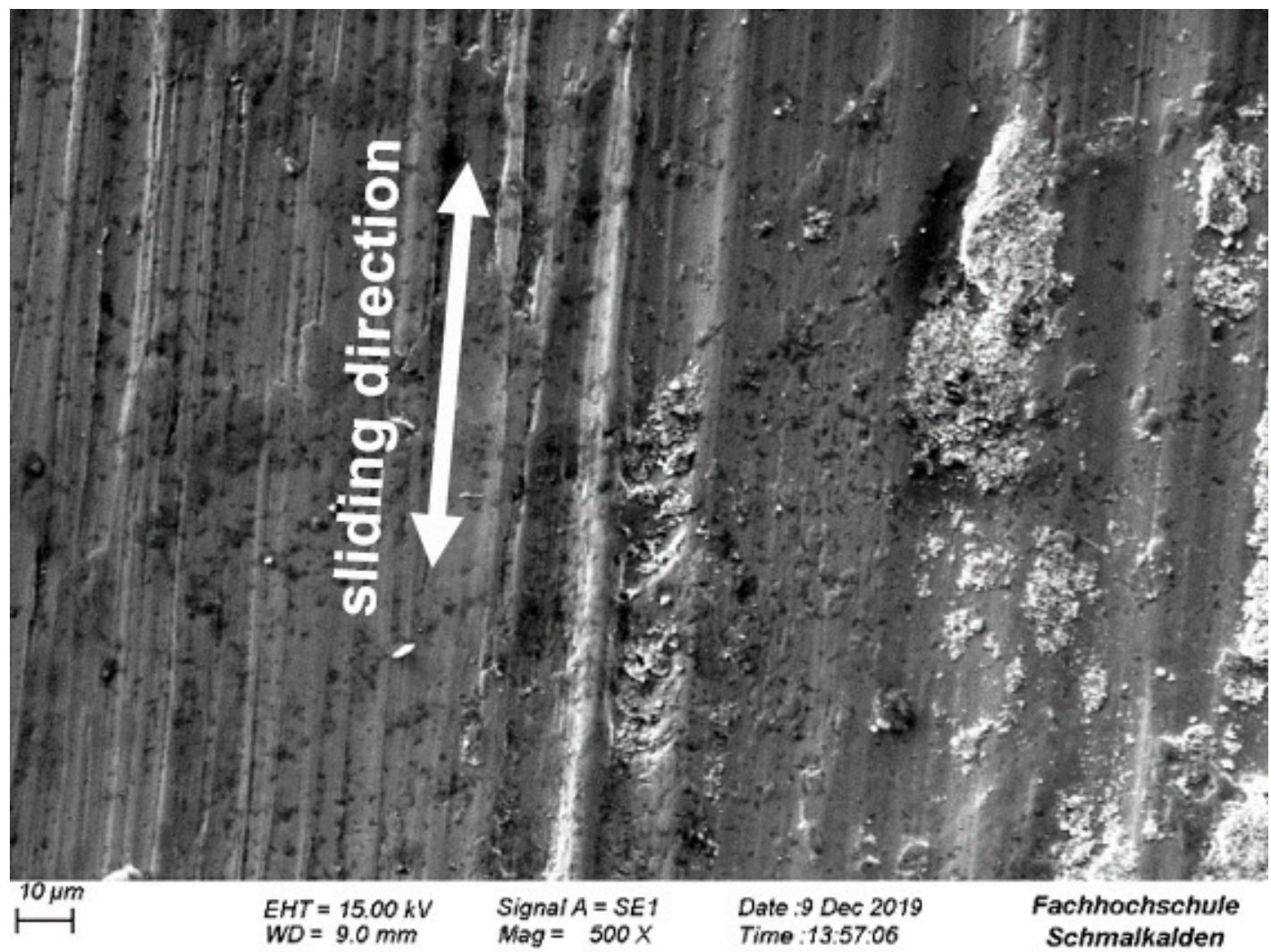

Figure 20. Wear trace CoCrMo disc without a-C:H coating after dry sliding of $\mathrm{ZrO}_{2}$ ball, $\left(\mathrm{F}_{\mathrm{n}}: 100 \mathrm{~N}\right.$, f: $1 \mathrm{~Hz})$, SEM.

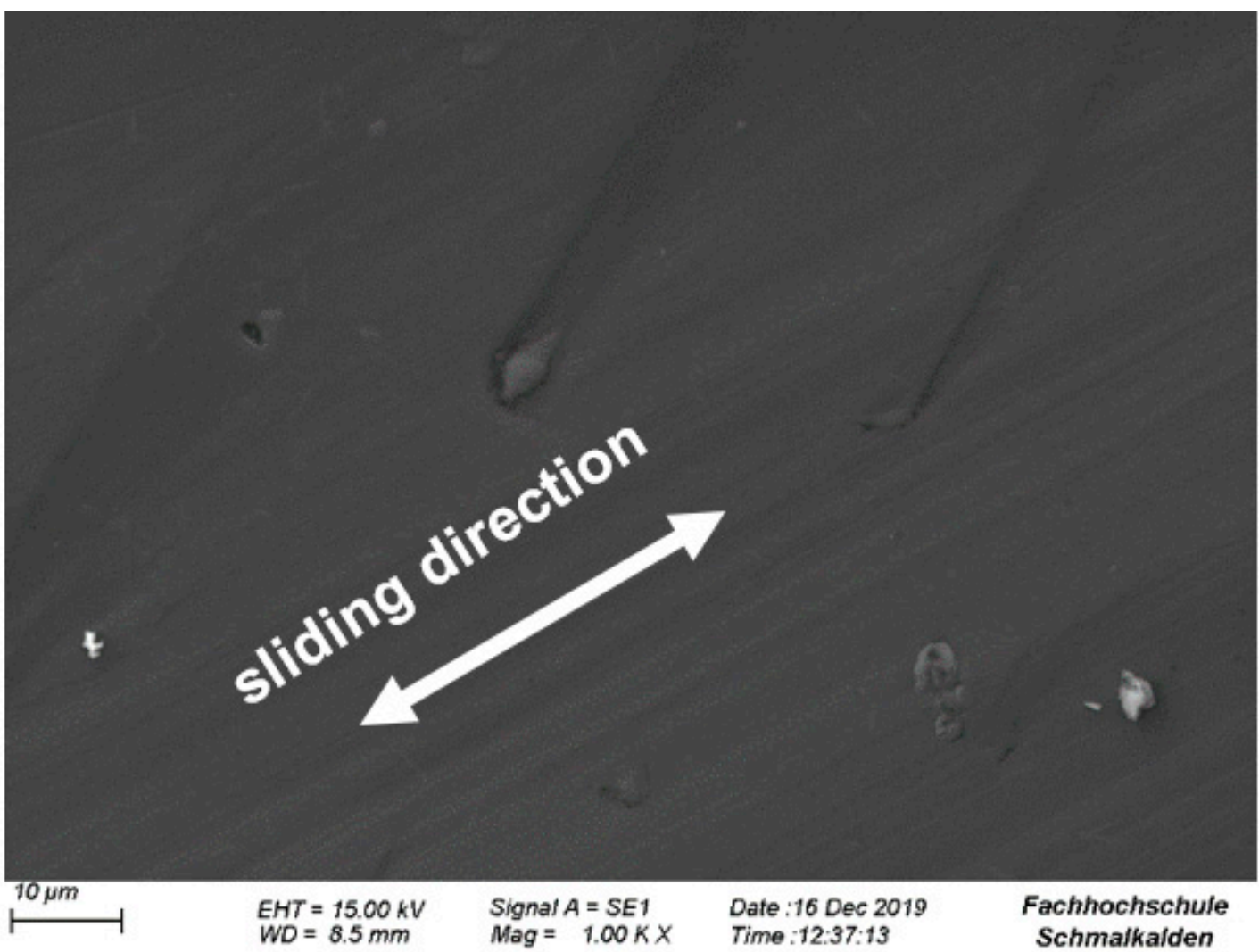

Figure 21. Wear trace $\mathrm{CoCrMo}(\mathrm{a}-\mathrm{C}: \mathrm{H})$ disc after dry sliding of $\mathrm{ZrO}_{2}$ ball, $\left(\mathrm{F}_{\mathrm{n}}: 100 \mathrm{~N}, \mathrm{f}: 1 \mathrm{~Hz}\right), \mathrm{SEM}$. 
The optical evaluation of the wear traces of zirconia balls are necessary for the calculation of the wear rate. In addition, the microscopic appearance of the circle-like wear traces in the zirconia balls gives insight into the wear phenomena. On the zirconia ball metallic transfer from the CoCrMo surface is seen, if sliding without DLC coating (Figures 22 and 23) and/or at high frequency of $50 \mathrm{~Hz}$ occurred.

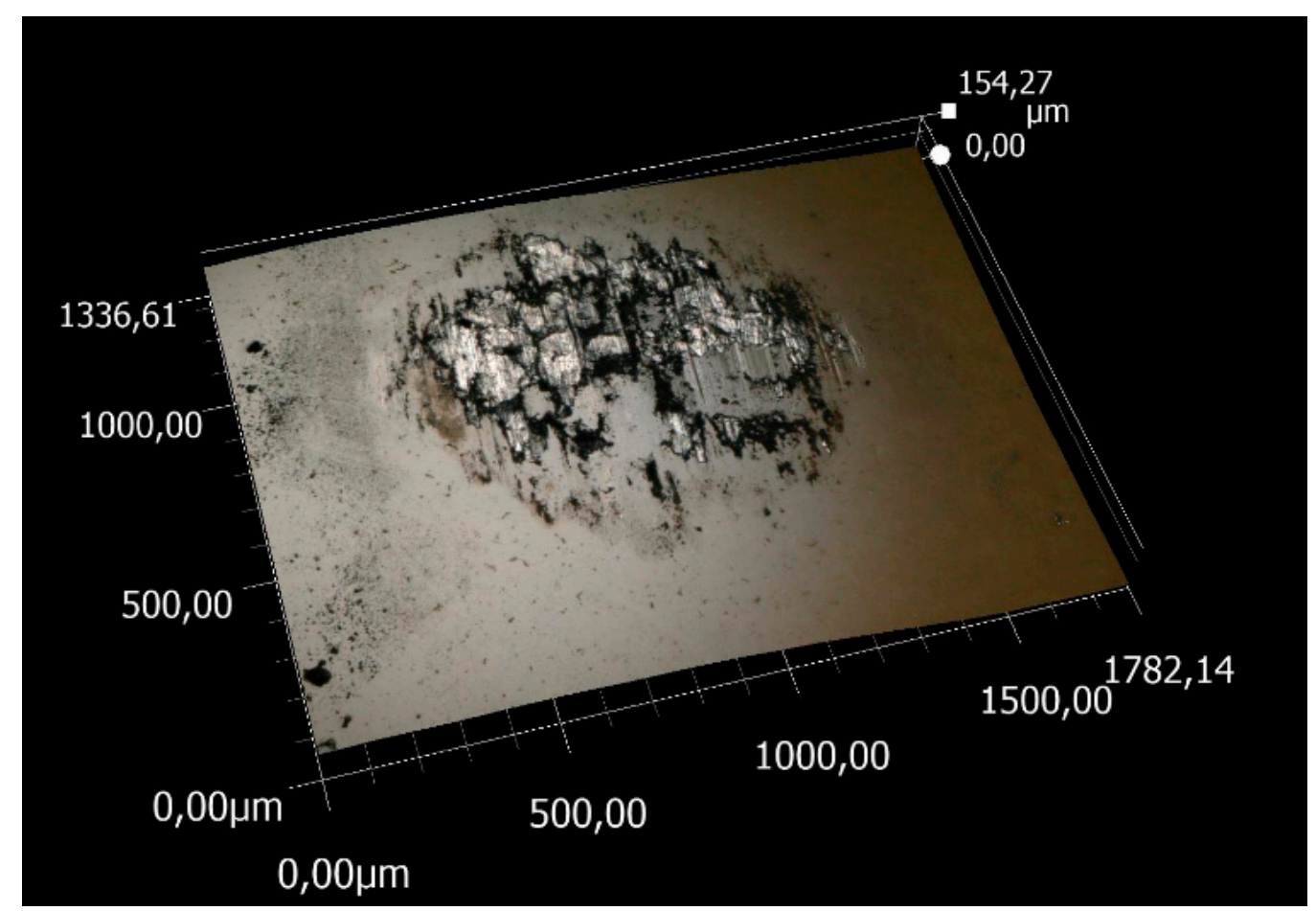

Figure 22. Wear marks on the surface of $\mathrm{ZrO}_{2}$ ball after sliding against the uncoated CoCrMo disc, $\mathrm{F}_{\mathrm{n}}: 100 \mathrm{~N}, \mathrm{f:} 1 \mathrm{~Hz}$, dry (3D image, digital microscopy).

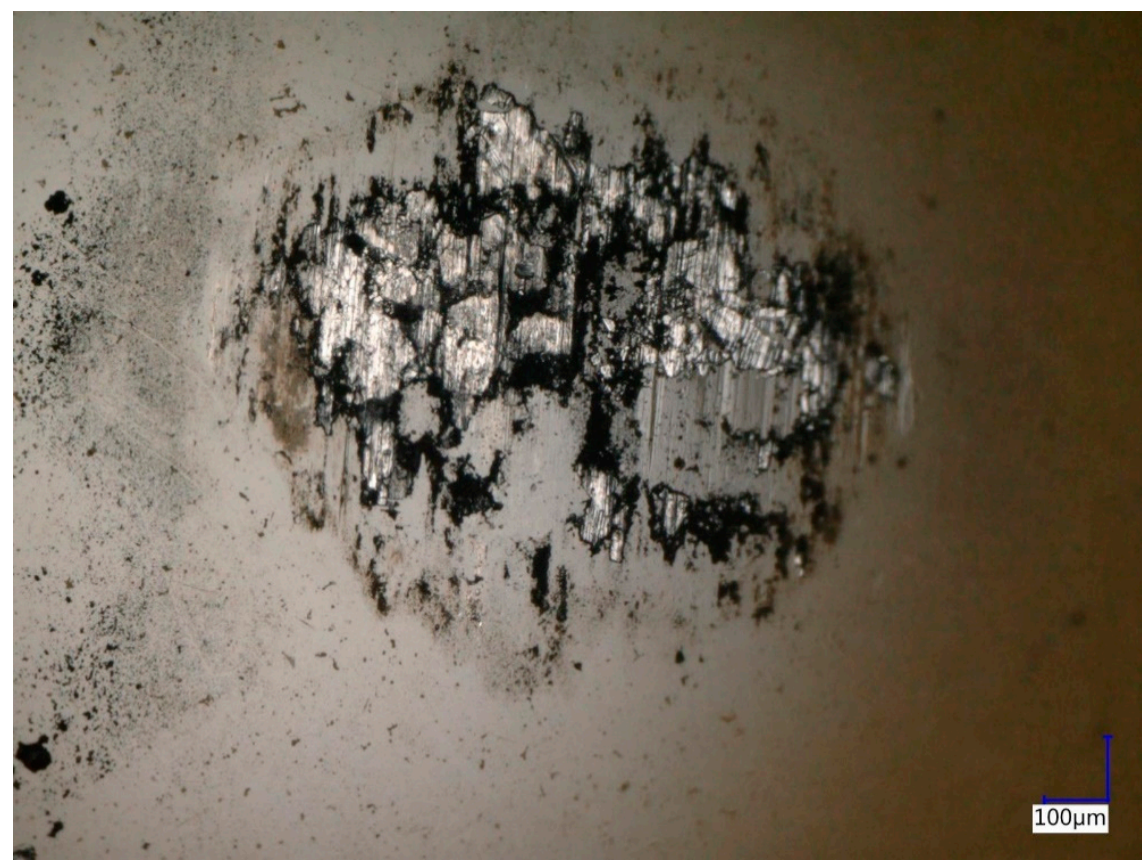

Figure 23. Wear marks on the surface of $\mathrm{ZrO}_{2}$ ball after sliding against the uncoated CoCrMo disc, $\mathrm{F}_{\mathrm{n}}: 100 \mathrm{~N}, \mathrm{f}: 1 \mathrm{~Hz}$, dry (2D image, digital microscopy). 
The a-C:H acts as a solid lubricant, but also is hard and wear resistant. No sign of material transfer from the disc was detected on the $\mathrm{ZrO}_{2}$ balls (Figures 24 and 25). The zirconia ball was scratched along the sliding direction. Finally, if there is hyaluronic gel as liquid lubricant between the zirconia ball and the diamond-like carbon coated CoCrMo, no wear trace was found at the $\mathrm{ZrO}_{2}$ balls surface after $1 \mathrm{~Hz}$ sliding (Figures 26 and 27).

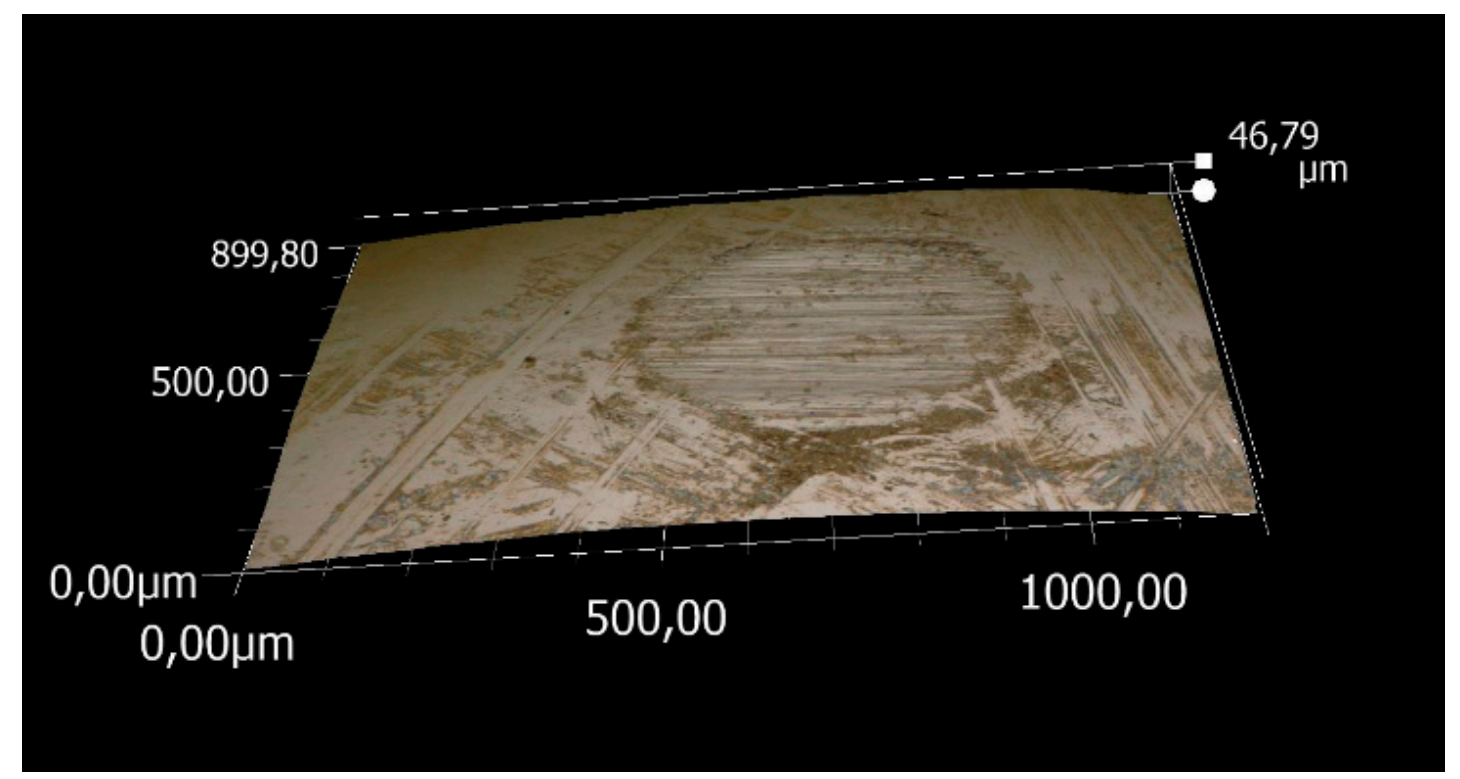

Figure 24. Wear marks on the surface of $\mathrm{ZrO}_{2}$ ball after sliding against the a-C:H-coated CoCrMo disc, $\mathrm{F}_{\mathrm{n}}: 100 \mathrm{~N}, \mathrm{f}: 1 \mathrm{~Hz}$, dry (3D image, digital microscopy).

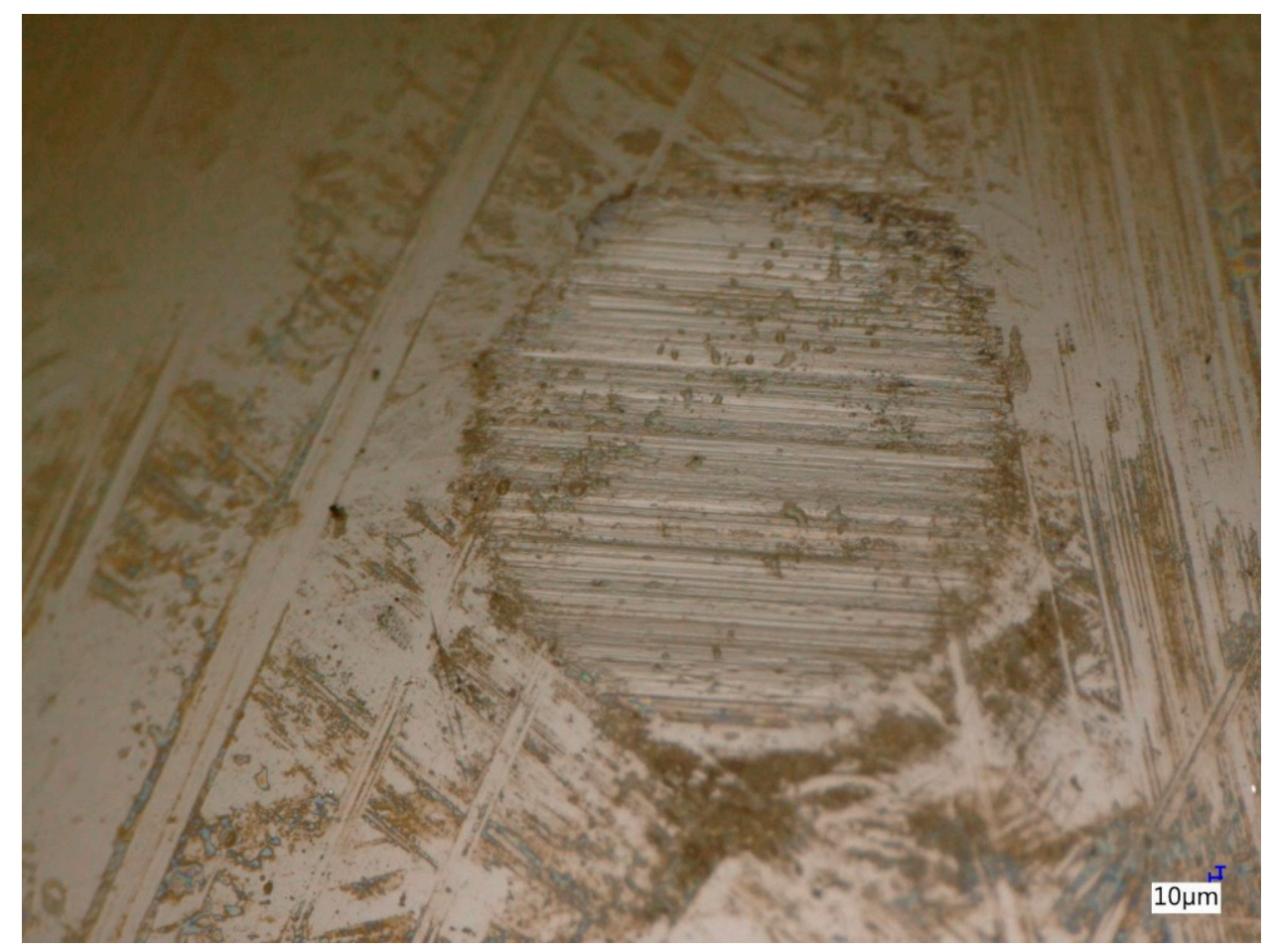

Figure 25. Wear marks on the surface of $\mathrm{ZrO}_{2}$ ball after sliding against the a-C:H-coated CoCrMo disc, $\mathrm{F}_{\mathrm{n}}: 100 \mathrm{~N}, \mathrm{f}: 1 \mathrm{~Hz}$, dry (2D image, digital microscopy). 


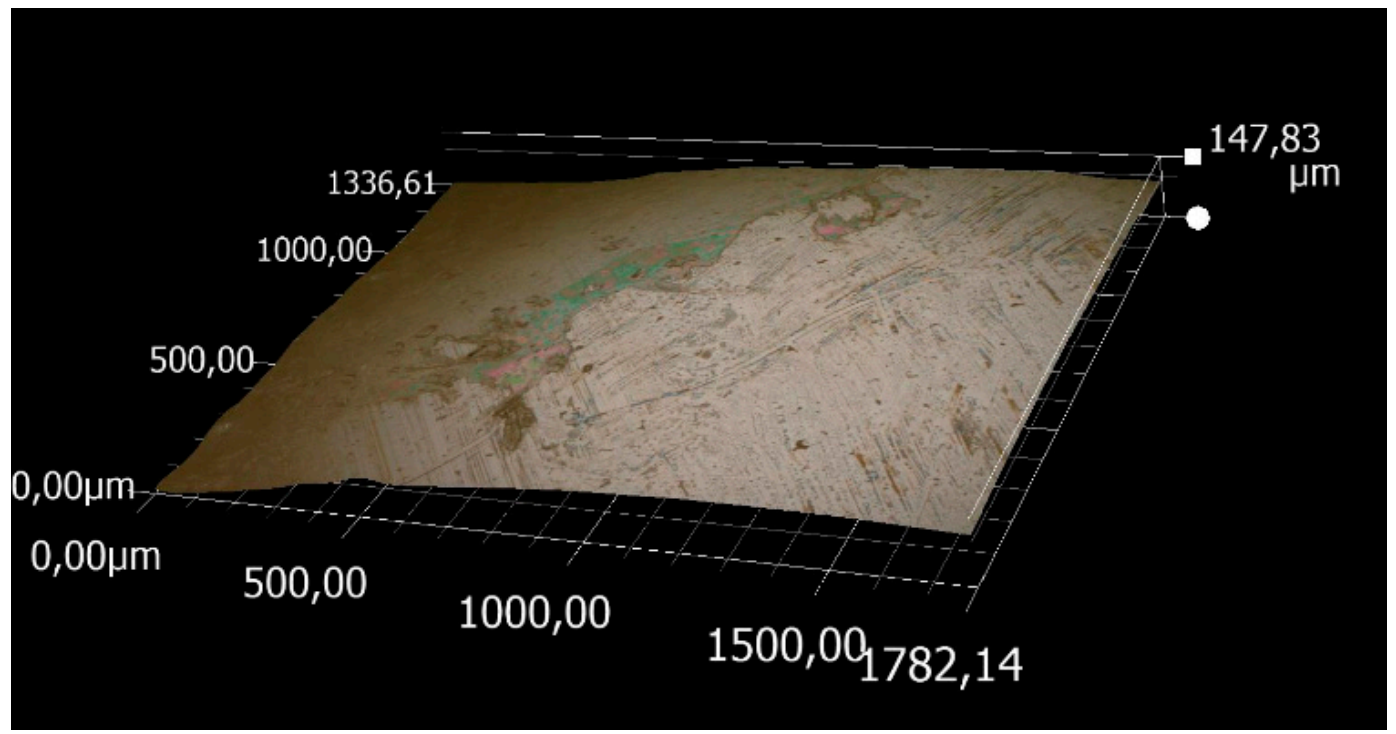

Figure 26. Wear marks on the surface of $\mathrm{ZrO}_{2}$ ball after sliding against the a-C:H-coated CoCrMo disc, $F_{n}: 100 \mathrm{~N}, \mathrm{f}: 1 \mathrm{~Hz}$, hyaluronic gel (3D image, digital microscopy).

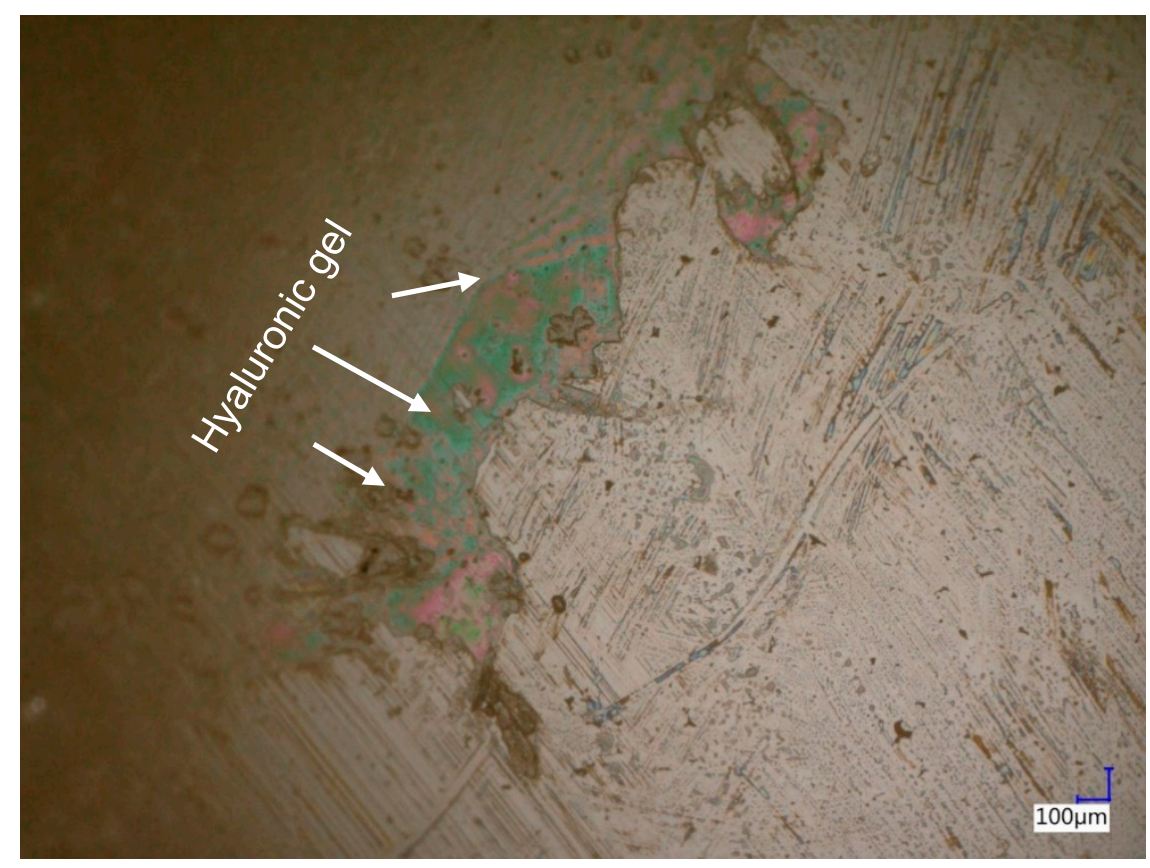

Figure 27. Wear marks on the surface of $\mathrm{ZrO}_{2}$ ball after sliding against the a-C:H-coated CoCrMo disc, $\mathrm{F}_{\mathrm{n}}: 100 \mathrm{~N}, \mathrm{f}: 1 \mathrm{~Hz}$, hyaluronic gel (2D image, digital microscopy).

\subsection{Raman Spectroscopy}

The Raman spectroscopic investigation on different positions on the surface of the diamond-like carbon coated CoCrMo confirm a stable position of the G-peak around $1542 \mathrm{~cm}^{-1}$. However, very different position of the D-peaks were obtained (Table 5; Figure 28). There is an upshifted D-peak position to higher wavenumbers in comparison to typical values for hydrogenated DLC (Figure 28). In addition, the $\mathrm{I}_{\mathrm{D}} / \mathrm{I}_{\mathrm{G}}$ ratios are declining, while the $\mathrm{I}_{\mathrm{D}} / \mathrm{I}_{\mathrm{G}}$ ratio decreases from 0.48 to 0.20 for the measurement with the most significant D-peak upshifting. Table 5 summarizes the measurement results from Raman spectroscopy on a-C:H coated medical grade CoCrMo before tribological loading. 
Table 5. Results from Raman spectroscopy $(\lambda=532 \mathrm{~nm})$ of a-C:H coated medical grade CoCrMo

\begin{tabular}{cccc}
\hline a-C:H, as Deposited & D Peak Position/cm & G Peak Position/ $\mathbf{c m}^{-\mathbf{1}}$ & $\mathbf{I}_{\mathbf{D}} / \mathbf{I}_{\mathbf{G}}$ Ratio \\
\hline $\begin{array}{c}\text { a-C:H, as deposited } \\
\text { position (1) }\end{array}$ & 1362.30 & 1541.29 & 0.48 \\
$\begin{array}{c}\text { a-C:H, as deposited } \\
\text { position (2) } \\
\text { a-C:H, as deposited } \\
\text { position (3) }\end{array}$ & 1384.07 & 1542.12 & 0.33 \\
\hline
\end{tabular}

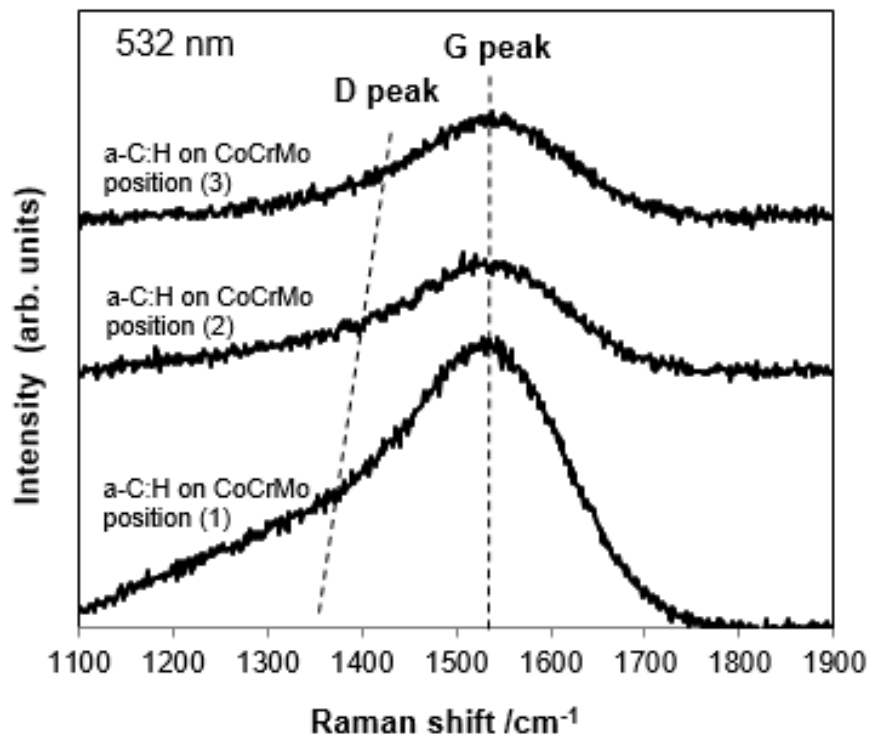

Figure 28. Raman spectra of a-C:H coatings on CoCrMo (as deposited and before wear tests).

Raman spectroscopy in the wear trace of a-C:H coated CoCrMo after dry sliding reveal no significant graphitization. The cracked and coherent failed a-C:H sections have almost the same $\mathrm{G}$ peak and D peak positions as the a-C:H before wear testing (Figure 29, Table 6). A minor shift of the G peak to higher wavenumbers like $1549.54 \mathrm{~cm}^{-1}$ (groove within the wear trace), $1547.33 \mathrm{~cm}^{-1}$ (crack within the wear trace), and $1545.22 \mathrm{~cm}^{-1}$ can be seen. The $\mathrm{I}_{\mathrm{D}} / \mathrm{I}_{\mathrm{G}}$ ratio is lowest within the a-C:H after coherent failure (Figures 21 and 30c). In this case, $\mathrm{I}_{\mathrm{D}} / \mathrm{I}_{\mathrm{G}}$ ratio is 0.22 , but remains in the same range as the values measured on "as deposited" a-C:H before the wear tests, which scattered a lot (Table 5). For the wear couple $\mathrm{ZrO}_{2}$ ball and a-C:H coated $\mathrm{CoCrMo}$ with hyaluronic gel as a lubricant, no change of the a-C:H microstructure were detected by Raman spectroscopy in this study also.

Table 6. Results from Raman spectroscopy $(\lambda=532 \mathrm{~nm})$ of a-C:H coated medical grade CoCrMo after wear tests $\left(\mathrm{F}_{\mathrm{n}}\right.$ : $100 \mathrm{~N}$; f: $1 \mathrm{~Hz}$; dry)

\begin{tabular}{|c|c|c|c|c|}
\hline & $\begin{array}{c}\text { CoCrMo(a-C:H) after } \mathrm{ZrO}_{2} \\
\text { Sliding (100 N; } 1 \text { Hz; Dry) }\end{array}$ & D Peak Position $/ \mathrm{cm}^{-1}$ & G Peak Position $/ \mathrm{cm}^{-1}$ & $\mathrm{I}_{\mathrm{D}} / \mathrm{I}_{\mathrm{G}}$ Ratio \\
\hline (a) & groove within the wear trace in a-C:H & 1408.81 & 1549.54 & 0.39 \\
\hline (b) & crack within the wear trace in a-C:H & 1412.01 & 1547.33 & 0.39 \\
\hline (c) & $\begin{array}{l}\text { deepening within the a-C:H wear } \\
\text { trace (coherent failure) }\end{array}$ & 1396.01 & 1545.22 & 0.22 \\
\hline (d) & $\begin{array}{l}\text { deepening within the wear trace } \\
\text { (after coating delamination) }\end{array}$ & - & - & - \\
\hline
\end{tabular}




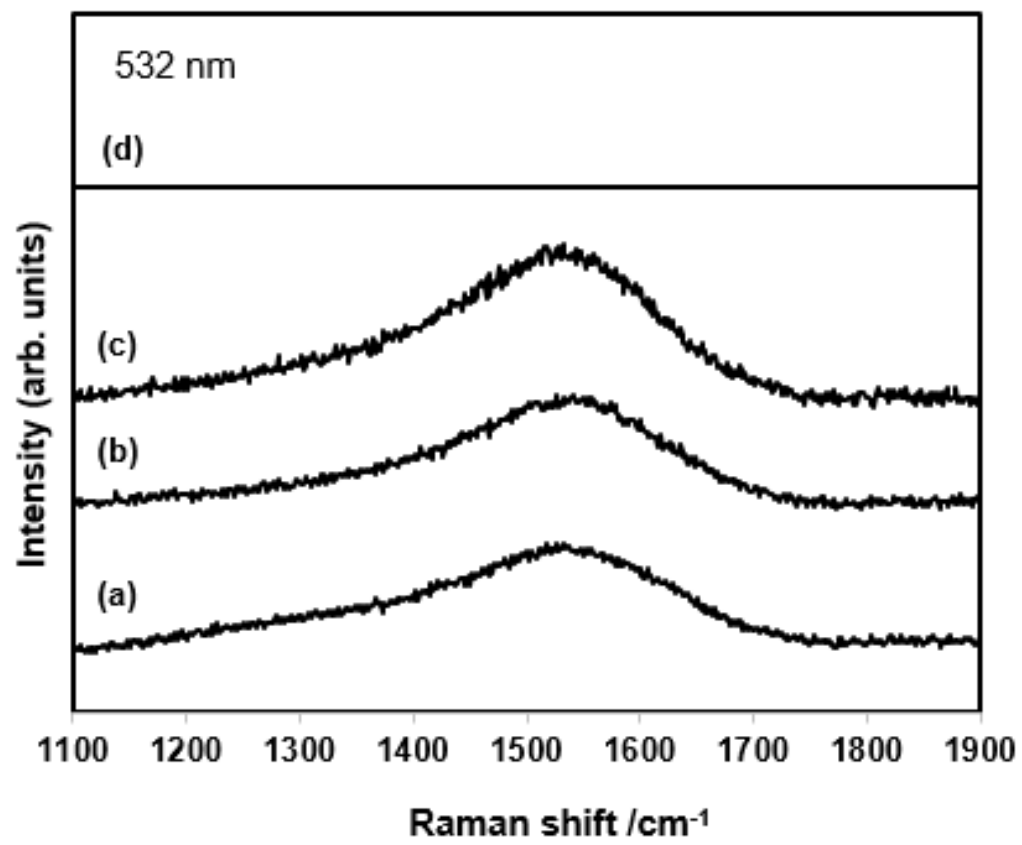

Figure 29. Raman spectra of hydrogenated a-C:H coatings on CoCrMo after wear tests w/o hyaluron-gel $\left(\mathrm{F}_{\mathrm{n}}: 100 \mathrm{~N}, \mathrm{f}: 1 \mathrm{~Hz}\right)(\mathrm{a})$ groove within the a-C:H wear trace, $(\mathbf{b})$ crack within the a-C:H wear trace, (c) coherent failure within the a-C:H wear trace, (d) CoCrMo substrate after delamination of the coating.
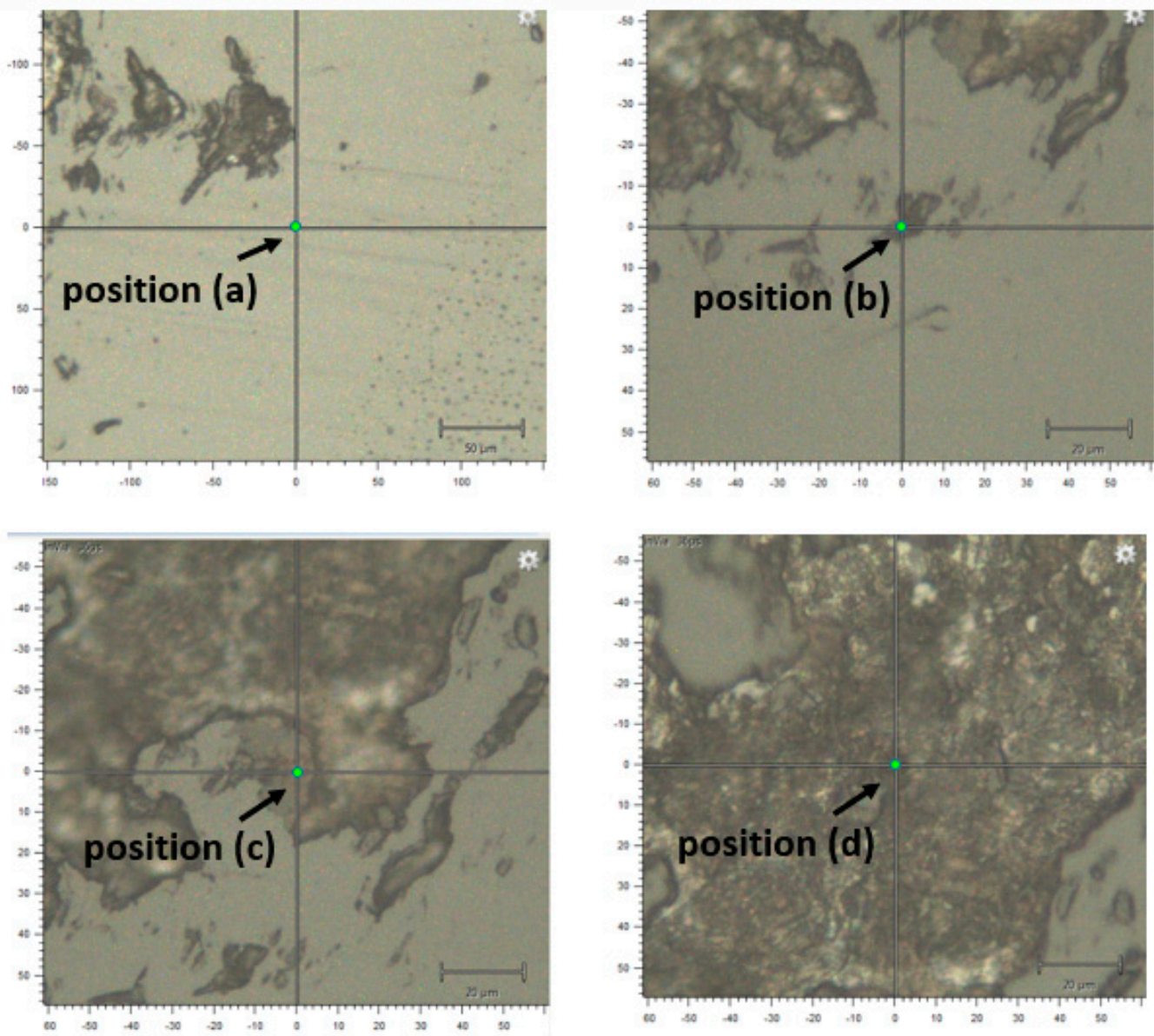

Figure 30. Measurement positions for Raman spectroscopy in the wear trace of a-C:H coated CoCrMo after dry sliding of $\mathrm{ZrO}_{2}$ ball $\left(\mathrm{F}_{\mathrm{n}}: 100 \mathrm{~N}, \mathrm{f}: 1 \mathrm{~Hz}\right)$. For explanation of $(\mathbf{a}-\mathbf{d})$ see Figure 29. 


\section{Discussion}

The movement of human joints, like hip or knee joints, is performed with moderate frequencies of about $1 \mathrm{~Hz}$ or lower. Furthermore, human joints are resting a lot. Situations with a start-stop algorithm are often. It is of eminent importance, that a low friction regime is ensured in the early stages of the relative movements between the two counterparts of the artificial joint. Therefore, a homogenous and enduring lubrication is essential. In the present study, the $1 \mathrm{~Hz}$ movement of the zirconia ball against the a-C:H coated CoCrMo is possible with a low coefficient of friction. The COF is around 0.1, but the initial run-in state from zero movement shows a high COF of 0.369 in dry environment. However, the natural movement habit of a human is characterized by plenty of start-stop cycles with such run-in situations. One can expect summation of high COF from such the run-in situations, and higher wear rates. Furthermore, during the sliding of the zirconia ball against the a-C:H coated $\mathrm{CoCrMo}$ with $1 \mathrm{~Hz}$ low frequency, there are sudden increases of the COF (Figure 10), which could be caused by switching between the static and the dynamic COF during the low speed movement on the medical grade surface. In addition, the tribology of a-C:H coatings is complex. There is the formation of a transfer film, which thickness and composition depend on different features. It is known that hydrogenated a-C:H develops its special low friction capacity under sufficient sliding. The later will stimulate the formation of a transfer film, which consists of carbon and hydrogen from the a-C:H structure. Scharf and Singer [16] report about the formation of a transfer film on hydrogenated a-C:H coatings at a low sliding speed of $1 \mathrm{~mm} / \mathrm{s}$. They measure changes in the transfer films thickness and accompanied fluctuations of COF from very low values of 0.05 to 0.5 in dry conditions (RH 3-4\%). With the evolution of the transfer film, Scharf and Singer [16] observed an overlapping of the Raman signals from the hosting a-C:H coating and the transfer film, which resulted in a common $G$ peak and an upshift of it. They declare that the COF remains in steady state until the transfer film thickness was less than $23-32 \mathrm{~nm} \pm 13 \mathrm{~nm}$. The change in transfer film thickness is possibly influenced by both, low sliding speed, and low humidity. Is the sliding minor, transfer film generation is moderate only. On the contrary, too high sliding speed would stimulate more heat and a certain thinning due to oxidation in air. With the selected $1 \mathrm{~Hz}$ and $50 \mathrm{~Hz}$ movement, these two extreme conditions are included.

For transfer film composition, the hydrogen evolution from the a-C:H needs to be considered. Hydrogen is set free during proper sliding from the a-C:H. It would be forced to a higher extent, if the sliding increases. Hydrogen satisfies the carbon bonds and stabilizes the transfer film structure and thickness.

Moving zirconia ceramic against a-C:H with higher sliding speeds than $1 \mathrm{~Hz}$ in dry atmosphere results in an impressing low COF. Wäsche and Klaffke et al. [17] measured COF of around 0.05 in dry air, and higher COF but still below 0.1 in normal and moist air. They report that no running in with a dangerous high initial COF occurred. Hydrogenated DLC is able to release the hydrogen during proper sliding. Initially, after a-C:H coating deposition, the hydrogen atoms are trapped in the a-C:H structure due to the plasma decomposition and excitation of the gaseous carbon-hydrogen precursor. There are atoms, charged ions, electrons, and neutral species and particle clusters in the $\mathrm{C}_{\mathrm{x}}-\mathrm{H}_{\mathrm{y}}$ plasma, which were forced with a certain energy to bombard the substrate. Hydrogen atoms can be included and trapped in holes of the diamond-like carbon network. Also, they can form bonds to $\mathrm{sp}^{2}$ - or $\mathrm{sp}^{3}$-hybridized carbon atoms. At first, during the initial sliding a kind of shearing of the structure of the loaded top section of a-C:H coating was observed in the present study. During this process, the atomic hydrogen will be stimulated and released. As mentioned before, it can contribute to the formation of a transfer layer. The importance of such hydrogen rearrangement in the a-C:H transfer films during sliding is described in detail by several research groups $[18,19]$. The tribochemical reaction of hydrogen with activated carbon, in which activation occurs due to the energy accumulation during sliding, leads to the formation of polymeric $\mathrm{C}-\mathrm{H}$ chains in the transfer films. The ongoing sliding process affects an orientation of the $\mathrm{C}-\mathrm{H}$ chains parallel to the sliding direction. Easy sliding with low $\mathrm{COF}$ is based on the low bonds between the aligned $\mathrm{C}-\mathrm{H}$ chains in this transfer film which allow easy slip off between the $\mathrm{C}-\mathrm{H}$ chains. By Raman spectroscopy, in the present study no graphitization of 
the a-C:H was detected in the wear traces. Raman spectra of a-C:H after the sliding of the $\mathrm{ZrO}_{2}$ ball reveal minor changes only, but a small upshift of the $G$ peak to higher wavenumbers. The degree of graphitization remains apparently low, but the before mentioned shearing were observed by SEM (Figure 21). Apparently, sliding under the chosen parameters $\left(\mathrm{F}_{\mathrm{n}}: 100 \mathrm{~N} ; \mathrm{f}: 1 \mathrm{~Hz}\right)$ affects shearing the a-C:H top surface mainly with no significant change in a-C:H structure as confirmed by Raman spectroscopy (Figure 29). A schematic visualizes this process (Figure 31).

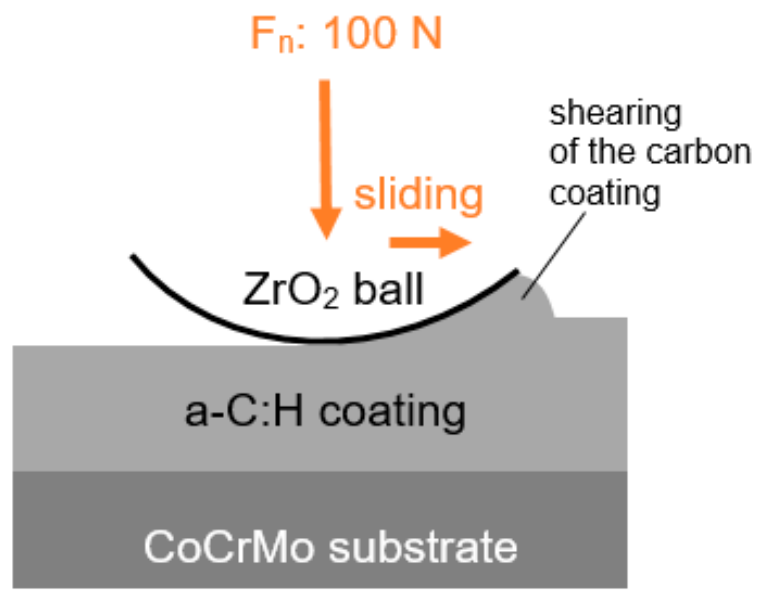

Figure 31. Shearing of a-C:H at the coatings surface with rearrangement of hydrogen during sliding is essential for transfer film formation.

At the edges of the wear trace after dry sliding of $\mathrm{ZrO}_{2}$ ball against a-C:H coating on $\mathrm{CoCrMo}$, the shearing of the a-C:H is shown by SEM as well (Figure 21). The most striking difference to the hyaluronic gel lubrication of $\mathrm{ZrO}_{2}$ against the hydrogenated amorphous carbon coating is the occurrence of a-C:H ablation under dry conditions. Apparently, changed load transfer into the a-C:H coated CoCrMo disc and temperature rises in the tribo zones effect damage. There is cracking and coating delamination in the center of the wear trace observable by SEM and digital microscopy (Figures 17 and 18) and Raman spectroscopy (Figures 29d and 30d, Table 6). Due to the cyclic sliding and the drastic differences in mechanical properties-such as Young's modulus, elastic limit and elongation of metallic $\mathrm{CoCrMo}$, and the inorganic diamond-like carbon coating-the extensive plastic deformation of the metallic substrate under high normal loads of $100 \mathrm{~N}$ start to throw off coating slices (Figure 32). This may be not occurring during lower normal loads, but in the present study extreme conditions-such as jumping of the patient with an a-C:H coated implant or maybe a wrong positioning of the implant—are considered.

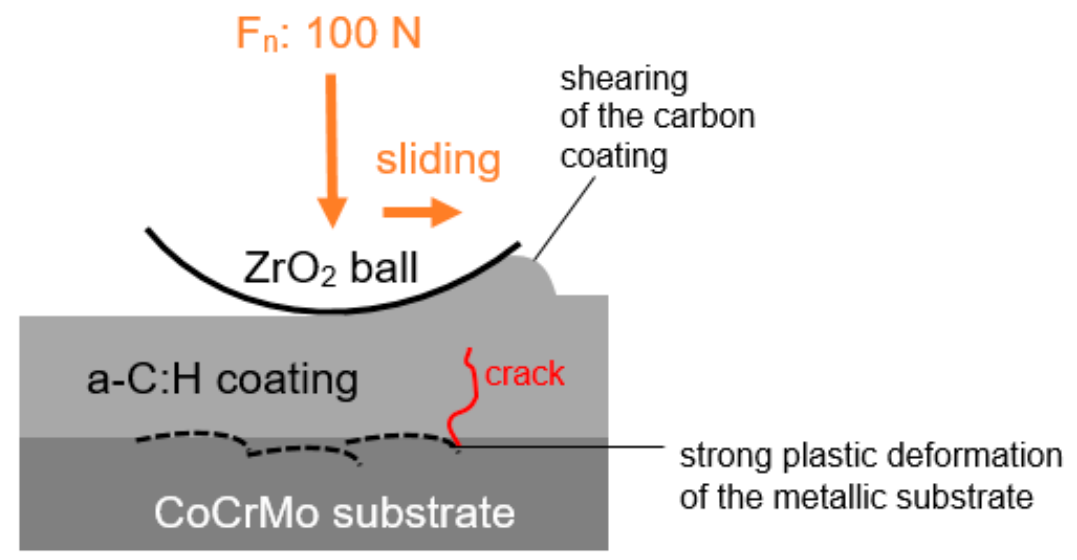

Figure 32. Cont. 


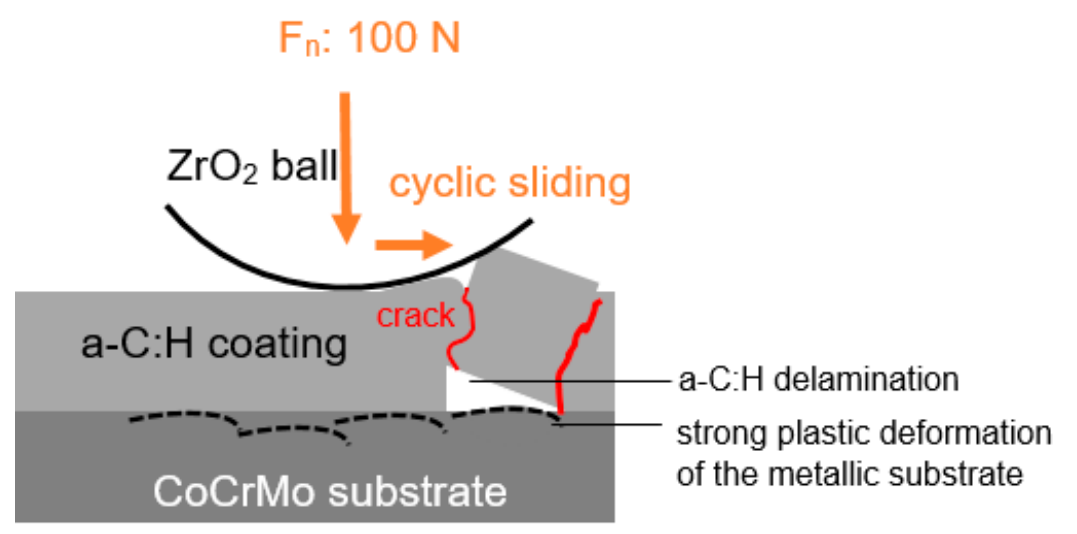

Figure 32. Plastic deformation of the substrate due to cyclic application of high loads and cyclic interfacial cracking with delamination.

A lubrication with hyaluronic gel results in a smooth and regular COF curve at $1 \mathrm{~Hz}$ movement. The COF is below 0.08 and no run-in stage with an initial very high COF is occurring (Figures 8 and 9). On the surface of the hydrogenated DLC, material shearing and minor scratching can be observed (Figure 21). Nevertheless, the wear rate of $0.16 \times 10^{-6} \mathrm{~mm}^{3} / \mathrm{Nm}$ for the disc a-C:H coated CoCrMo remains about two orders of magnitude lower in comparison to dry sliding of zirconia against a-C:H with a wear rate of the disc of $21.09 \times 10^{-6} \mathrm{~mm}^{3} / \mathrm{Nm}$. It underlines the fact that lubrication plays an essential role in durability of diamond-like carbon and the ability to unfold its performance and unique properties in biomedical joints. It is known to reduce shock, vibration surface fatigue, and changes the load transfer into the base body of the tribological system. A cooling of the tribological system can be expected. This is advantageous for a-C:H as well, because diamond-like carbons endure moderate temperature rise only.

The increase in COF of the hyaluronic gel lubricated zirconia sliding against the a-C:H surface of the $\mathrm{CoCrMo}$ may be attributed to the observed change of viscosity of hyaluronic gel. Its $\mathrm{COF}_{30}$ reaches the level of non-lubricated a-C:H at $1 \mathrm{~Hz}$ sliding. It may be attributed to a reduction in the lubricating effect. The lubrication conditions seem to be in the region of mixed or boundary lubrication only. Otherwise, no scratching or shearing would occur at the a-C:H surface. In the boundary mode lubrication of cartilage-cartilage, the relative effectiveness of friction reduction has been shown to be dependent on the molecular weight of hyaluronic acid with higher molecular weight resulting in lower friction [20,21]. Bonnevie et al. [22] showed that the lubricating effect of hyaluronic acids with different viscosities widely varies with no correlation to the frictional behavior. They argue that for highly viscous polymeric solutions like studied hyaluronic acids wall slip and interfacial effects need additional consideration and can alter the lubrication drastically. Friction coefficients of the real biomedical counterparts as measured in this study give a better correlation to the wear behavior.

The solid-solid contact between ceramic $\mathrm{ZrO}_{2}$ ball and metallic CoCrMo alloy without a-C:H coating and hyaluronic gel lubrication is leading to a tremendous wear rate of both ball and metallic alloy. Applying $1 \mathrm{~Hz}$ for $30 \mathrm{~min}$ results in a wear rate of the disc of $67.01 \times 10^{-6} \mathrm{~mm} / \mathrm{N} \cdot \mathrm{m}$, while $50 \mathrm{~Hz}$ for results in a wear rate of $77.37 \times 10^{-6} \mathrm{~mm}^{3} / \mathrm{N} \cdot \mathrm{m}$ for the disc. Increasing the frequency worsens the situation and material loss by strong adhesive and abrasive wear, as expected. Surprisingly, the wear rate of the $\mathrm{ZrO}_{2}$ ball was lower at higher frequency with a value of $13.19 \times 10^{-6} \mathrm{~mm}^{3} / \mathrm{N} \cdot \mathrm{m}$ in comparison to the $1 \mathrm{~Hz}$ sliding with a 3-fold higher $\mathrm{ZrO}_{2}$ balls wear rate of $39.13 \times 10^{-6} \mathrm{~mm}^{3} / \mathrm{N} \cdot \mathrm{m}$. It was observed by microscopic methods in this study, that during $50 \mathrm{~Hz}$ sliding, smearing, adhesive wear of $\mathrm{CoCrMo}$ after a coating failure are dominating the wear process, while the ceramic ball remains less damaged.

If the $\mathrm{ZrO}_{2}$ ball slides against the a-C:H coated medical grade CoCrMo with $1 \mathrm{~Hz}$ and $100 \mathrm{~N}$ normal force, the lowest wear rate with $0.16 \times 10^{-6} \mathrm{~mm}^{3} / \mathrm{N} \cdot \mathrm{m}$ were reached with hyaluronic gel lubrication. Although, an extreme high normal load was applied and unusual low sliding speed of 
$1 \mathrm{~Hz}$ were chosen, the a-C:H carried the load and was not worn through, nor delaminated. $\mathrm{The}_{\mathrm{ZrO}}$ ball showed no sign of wear at all (Figures 26 and 27), if lubrication with hyaluronic gel was applied. The hyaluronic gel wetting was excellent. After the tests, it was hard to remove the dried hyaluronic residuals from the ball and the disc.

The $50 \mathrm{~Hz}$ sliding with $100 \mathrm{~N}$ normal load is an even more drastic loading of the biomedical materials. However, also in this extreme situation, the a-C:H coating reduced the wear rate and ensure a certain time low COF of about 0.1 (Figure 7), if the hyaluronic gel lubrication can be ensured. Due to the high frequency loading, a temperature increase in the tribological contact zone can contribute to the failure of a-C:H in this case additionally. Care needs to be taken to design a biomedical implant, which enables sufficient thermal conductivity for both, the stability of a-C:H coating and the prevention of quality of the hyaluronic gel as well as enduring lubrication.

\section{Conclusions}

An a-C:H coating can be useful for preventing metallic ions and particle loosening from CoCrMo alloys. The undesired migration of metallic ions and particles in the body is associated with tissue reaction as well as body liquids and protein interactions. A durable coating ensures long-term protection. As shown in this study, in cases of occasional overloading or ongoing start-stop movements, the COF can suddenly increase, if no homogenous lubrication is ensured. Hyaluronic gel lubrication provides an excellent protection against occasional overloading of biomedical materials during extreme movement or implant de-arrangement. In order to ensure homogeneous lubrication during the life span of the implant, measures need to be implemented for continuous supply of hyaluronic lubricant. Such measures can include proper macroscopic design of the implants and/or micropatterning of the surface. Furthermore, to prevent coating delamination in cases of occasional overloading or ongoing start-stop movements with initial high COF during the run-in stage, adherence of the coating should be improved by different measures. There are manifold options to reach improved coating stability in addition to mere graded a-C:H microstructures. Supporting interlayers—such as TiC, TiAlC, TiAlN, TiAlC, and $\mathrm{SiN}_{\mathrm{x}}$ interlayer-are state of the art or state of research [23-26] for several applications. The long-term effect of any interlayer in biomedical environment and other changes on the tribological system need to be verified.

Author Contributions: C.S.: PE-CVD deposition of a-C:H coatings; S.S.: Microscopic investigations; A.D.-R.: Raman spectroscopy and wear tests. All authors have read and agreed to the published version of the manuscript.

Funding: The support for the Article Processing Charge by the Thuringian Ministry for Economic Affairs, Science and Digital Society is acknowledged. In addition, authors are grateful for the financial support of the project BUNT 2015-0012 "Biogenic different nanostructured high performance carbons" which enabled Raman spectroscopy. Furthermore, the authors thank the Arbeitsgemeinschaft industrieller Forschungsvereinigungen AiF "Otto von Guericke" e.V. for financial funding of the project IGF015/03 and the Deutsche Forschungsgemeinschaft DFG for financial support of the project DO 660-1.

Conflicts of Interest: The authors declare no conflict of interest.

\section{References}

1. Kung, M.S.; Markantonis, J.; Nelson, S.D.; Campbell, P. The synovial lining and synovial fluid properties after joint arthroplasty. Lubricants 2015, 3, 394-412. [CrossRef]

2. Posada, O.M.; Tate, R.J.; Meek, D.; Grant, M.H. In vitro analysis of toxicity, immunological, and gene expression effects of cobalt-chromium-alloy wear debries and Co ions derived from metal-on-metal hip implants. Lubricants 2015, 3, 539-568. [CrossRef]

3. Fuhrer, E.; Bäcker, A.; Kraft, S.; Gruhl, F.J.; Kirsch, M.; MacKinnin, N.; Korvik, J.G.; Sharma, S. 3D Carbon Scaffolds for Neural Stem cell culture and magnetic resonance imaging. Adv. Healthc. Mater. 2018, 7, 1-7. [CrossRef]

4. Patel, A.; Mukundan, S.; Wenhu, W.; Karumuri, A.; Sant, V.; Mukhopadhyay, S.M.; Sant, S. Carbon-based hierarchical scaffolds for myoblast differentiation: Synergy between nano-functionalization and alignment. Acta Biomater. 2016, 32, 77-88. [CrossRef] [PubMed] 
5. $\quad$ Eivazzadeh-Keihan, R.; Maleki, A.; de la Guardia, M.; Bani, M.S.; Chenab, K.K.; Pashazadeh-Panahi, P.; Baradaran, B.; Mokhtarzadeh, A.; Hamblin, M.R. Carbon based nanomaterials for tissue engineering of bone: Buidling new bone on small black scaffolds: A review. J. Adv. Res. 2019, 18, 185-201. [CrossRef] [PubMed]

6. Stankova, L.; Musilkova, J.; Broz, A.; Potocky, S.; Kromka, A.; Kozak, H.; Izak, T.; Artemenko, A.; Stransa, D.; Barcakova, L. Alteration to the adhesion, growth and osteogenetic differentiation of human osteoblast-like cells on nanofibrous polylactide scaffolds with diamond nanoparticles. Diam. Relat. Mater. 2019,97,107421-107426. [CrossRef]

7. Ngu-Schwemlein, M.; Chin, S.F.; Hileman, R.; Drozdowski, C.; Upchurch, C.; Hargrove, A. Carbon nanodots as molecular scaffolds for development of antimicrobial agents. Bioorg. Med. Chem. Lett. 2016, 26, 1745-1749. [CrossRef]

8. Xue, J.L.; Wu, B.J.; Zhang, T.F.; Leng, Y.X.; Huang, N. Tribocorrosion behaviour of DLC-coated CoCrMo alloy in simulated biological environment. Vacuum 2013, 92, 39-42. [CrossRef]

9. Xiang, D.D.; Sui, X.D.; Ran, X.P.; Hao, J.Y.; Wang, Z.W.; Liao, Z.H.; Liu, W.Q.; Tor, S.B. Improving biotribological properties and corrosion resistance of CoCrMo alloy via a Cr-GLC nanocomposistes film in simulated body fluids. Surf. Coat. Technol. 2019, 378, 124840. [CrossRef]

10. Dorner-Reisel, A.; Schuerer, C.; Müller, E. The wear resistance of diamond-like carbon coated and uncoated Co28Cr6Mo knee prostheses. Diam. Relat. Mater. 2004, 13, 823-827. [CrossRef]

11. Dorner-Reisel, A.; Gärtner, G.; Reisel, G.; Irmer, G. Diamond-like carbon films for polyethylene femoral parts: Raman and FT-IR spectroscopy before and after incubation in simulated body liquid. Anal. Bioanal. Chem. 2008, 390, 1487-1493. [CrossRef] [PubMed]

12. Tanaka, Y.; Nakamura, S.; Kuriyamma, S.; Nishitani, K.; Ito, H.; Fufu, M.; Watanabe, M.; Matsuda, S. Medical tilting of the joint line in posterior stabilized total knee arthroplasty increases contact force and stress. Clin. Biomech. 2019, 53, 54-59. [CrossRef] [PubMed]

13. Valenzuela, K.A.; Zhang, S.; Schroeder, L.E.; Weinhardt, J.-T.; Cates, H.E. Increased knee loading in stair ambulation in patients dissatisfied with their total knee replacement. Clin. Biomech. 2019, 67, 38-44. [CrossRef] [PubMed]

14. Erceg, M. The influence of femoral head shift on hip biomechanics: Additional parameters accounted. Intern. Orthop. 2009, 33, 95-100. [CrossRef]

15. Robertson, J. Classification of Diamond-like Carbon. In Tribology of Diamond-Like Carbon Films, 1st ed.; Donnet, C., Erdemir, A., Eds.; Springer Science: New York, NY, USA, 2008; pp. 13-24.

16. Scharf, T.W.; Singer, I.L. Third Bodies and Tribochemistry of DLC Coatings. In Tribology of Diamond-Like Carbon Films, 1st ed.; Donnet, C., Erdemir, A., Eds.; Springer Science: New York, NY, USA, 2008; pp. 201-236.

17. Wäsche, R.; Klaffke, D. Tribology of DLC Films Under Fretting Conditions, 1st ed.; Donnet, C., Erdemir, A., Eds.; Springer Science: New York, NY, USA, 2008; pp. 362-382.

18. Sugimoto, I.; Miyake, S. Oriented hydrocarbons transferred from a high performance lubricative amorphous C:H:Si films during sliding in a vacuum. Appl. Phys. Lett. 1990, 56, 1868-1870. [CrossRef]

19. Fontaine, J.; Donnet, C.; Grill, A.; Le Mogne, T. Tribochemistry between hydrogen and diamond-like carbon films. Surf. Coat. Technol. 2001, 146, 286-291. [CrossRef]

20. Kwiecinski, J.J.; Dorosz, S.G.; Ludwig, T.E. The effect of molecular weight on hyaluronan's cartilage boundary lubricating ability-alone nd in combination with proteoglycan. Ostheoarthritis Cartil. 2011, 19, 1356-1362. [CrossRef]

21. Crowman, M.K.; Schmidt, T.A.; Raghavan, P.; Stecco, A. Viscoelastic properties of hyaluronan in physiological conditions. F1000Research 2015, 4, 622-635. [CrossRef]

22. Bonnevie, E.D.; Galesso, D.; Secchieri, C.; Bonassar, L.J. Frictional characterization of injectable hyalurinc acids is more predictive of clinical outcomes than traditional rheological or viscoelastic characterization. PLoS ONE 2019, 14, e02216702. [CrossRef]

23. Schürer, C.; Semmler, U. Advanced Applications of Diamond-like Carbon Coatings, Lecture at EUROMAT 1999 on Sept 28th 1999 in Munich, GERMANY.

24. Wu, Y.M.; Liu, J.Q.; Cao, h.T.; Wu, Z.Y.; Wang, Q.; Ma, Y.P.; Jiang, H.; Wen, F.; Pei, Y.T. On the adhesion of DLC films deposited on nitrile butadiene rubber: A Ti-C interlayer. Diam. Relat. Mater. 2020, 101, 107563. [CrossRef] 
25. Chen, Q.; Zheng, C.; Xu, H.; Lv, H.; Wang, Z.; Wang, X. Effect of SiNx interlayer thickness on adhesion and friction properties of diamond-like carbon films. Diam. Relat. Mater. 2019, 94, 186-193. [CrossRef]

26. Kang, S.; Lim, H.-P.; Lee, K. Effects of TiCN interlayer on bonding characteristics and mechanical properties of DLC-coated Ti-6Al-4V ELI alloy. Intern. J. Refract. Met. Hard Mat. 2015, 53A, 13-16. [CrossRef]

(C) 2020 by the authors. Licensee MDPI, Basel, Switzerland. This article is an open access article distributed under the terms and conditions of the Creative Commons Attribution (CC BY) license (http://creativecommons.org/licenses/by/4.0/). 